\title{
Neurotoxinas de anêmonas do mar como ferramentas para o estudo da fisiologia de canais voltagem - dependentes de potássio
}

Sea anemones neurotoxins as tools to study the physiology of voltage-gated potassium channels.

\section{Diego Tose Belato y Orts}




\title{
Diego Jose Belato y Orts
}

\section{SEA ANEMONES NEUROTOXINS AS TOOLS TO STUDY THE PHYSIOLOGY OF VOLTAGE-GATED POTASSIUM CHANNELS}

\author{
Neurotoxinas de anêmonas do mar como ferramentas para o estudo da \\ fisiologia de canais voltagem - dependentes de potássio.
}

Dissertação apresentada ao Instituto de Biociências da Universidade de São Paulo, para a obtenção do Título de Mestre em Ciências, na Área de Fisiologia Geral.

\section{Orientadores:}

José Carlos de Freitas

(Fevereiro de 2010 a Fevereiro de 2011)

José Eduardo Pereira Wilken Bicudo

(Fevereiro de 2011 a Fevereiro de 2013)

\author{
São Paulo
}




\section{Diego Jose Belato y Orts}

AUTORIZO A REPRODUÇÃO E DIVULGAÇÃO TOTAL OU PARCIAL DESTE TRABALHO, POR QUALQUER MEIO CONVENCIONAL OU ELETRÔNICO,

PARA FINS DE ESTUDO E PESQUISA, DESDE QUE CITADA A FONTE.

FICHA CATALOGRÁFICA ELABORADA PELA BIBLIOTECA DO INSTITUTO DE BIOCIÊNCIAS DA UNIVERSIDADE DE SÃO PAULO

Orts, Diego Jose Belato

Neurotoxinas de anêmonas do mar como ferramentas para o estudo da fisiologia de canais voltagem - dependentes de potássio / Diego Jose Belato Orts ; orientador José Eduardo Pereira Wilken Bicudo. - São Paulo, 2013.

$92 \mathrm{f}$.

Dissertação (Mestrado) - Instituto de Biociências da Universidade de São Paulo. Departamento de Fisiologia Geral.

1. Toxinologia. 2. Anêmonas do mar. 3. Neurotoxinas. 4. Canais voltagem - dependentes de $\mathrm{K}^{+}$. I. Universidade de São Paulo. Instituto de Biociências. Departamento de Fisiologia Geral.

\section{Comissão Julgadora:}

Prof. Dr. José Eduardo Pereira Wilken Bicudo

Prof. Dr.

Prof. Dr. 
"At Vniversidade é um local onde se ensina porque se pesquisa

Carlos Chagas Filho 
Gostaría de agradecer aos meus pais, por acreditarem que a educação e a cultura são essenciais para o desenvolvimento de uma sociedade e, em especial, para o crescimento de seus filhos. Agradeço pelas inúmeras sítuações em que eles foram altruistas, privando-se de bens e consumo, pois acreditavam que valia mais a pena investir no futuro de um cidadão. Se não fosse por eles, tería sido impossivel ter a oportunidade, neste momento, de agradecer às inúmeras pessoas que fizeram e ainda fazem parte da minha vida pessoal e acadêmica! Agradeço também ao meu irmão e aos meus familiares por sempre terem me apoiado e contribuido para o men desenvolvimento.

Agradeço à minha querida companheira, Luana valente senise, que esteve presente comigo em todos esses anos. Sempre me apoiando e aconselhando-me nos váríos momentos delicados. Agradeço por compreender a importância que a minha ausêncía tería para o meu crescimento profissional e para o nosso crescimento pessoal. Peço desculpas pelas noítes mal dormidas e pelos momentos de impaciência! sem duvida a tua constante presença foi responsável por grandes melhorías na minha vida.

Agradeço ao professor josé carlos de Frétas por ter me dado à oportunidade de trabalhar em seu laboratório e, ao prof. José Eduardo Pereira Wilken Bicudo, por ter aceitado a minha orientação em 2012, quando o prof. Freitas passou por uma serie de problemas pessoais que o impossibilitaram de continuar trabalhando. Agradeço imensamente pela confiança que o prof. Bicudo depositon em mim e, pelos conselhos em momentos dificeis! sem duvida, muitos destes ensinamentos foram importantes para o meu crescimento pessoal e serão úteis ao longo da minha vida acadêmica.

Agradeço ao Mestre Bruno Madio que teve uma contribuição intelectual muito relevante para o desenvolvimento 
do meu Mestrado. As intermináveis conversas, propostas de projeto e delineamentos experimentais nunca serão esquecidos. sou grato também pela sua sincera amizade, algo que em minha opinião é muito dificil de encontrar no méio acadêmico.

Agradeço à Dra. Juliana Sílva cassolí e Dra. Camíla Takeno cologna por terem me ajudado ao longo desses anos e pelas várías noítadas regadas a muita cerveja belga, que nunca serão esquecidas. Agradeço também ao Steve Peigneur e Beatriz García Mílle por todo suporte ao longo da minha estadia em Leuven e, obviamente, pela amizade que se formou!

Agradeço ao Eduardo, da Tesouraría do instituto de Biociências, pelas inúmeras dicas que com certeza me ajudaram e, evitaram que en me afundasse em um labirinto burocrático. À sra. cristine e $\mathrm{Sr}^{a}$. Yoco, da Administração do IB, por terem me ajudado em todo o trâmite envolvido na compra dos reagentes que foram utilizados ao longo da minha estadia na Bélgíca. Agradeço também ao Díretor do B, o prof. Carlos Eduardo Falavigna da Rocha, por ter acreditado na qualidade do meu projeto de pesquisa e, ter financiado grande parte da compra dos reagentes necessários.

Agradeço à Roseli, secretáría do Programa de Pósgraduação em Fisiología, por sempre ter me ajudado em tudo o que eu precisé e, ao então coordenador da Pós-graduação, prof. josé Guilherme chaui-Berlincle por ter me dado todo o suporte necessário durante o processo de alteração da minha orientação, sempre zelando para que eu não fosse academicamente prejudicado.

Por fim, agradeço aos meus amigos de longa data e, às amizades que se formaram ao longo desses anos. Uma vida social é essencial para a sanidade mental de um pósgraduando! 


\section{Índice}

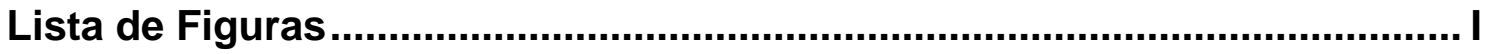

Lista de Tabelas

Lista de símbolos e Abreviaturas .............................................................

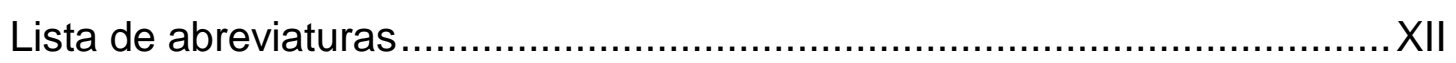

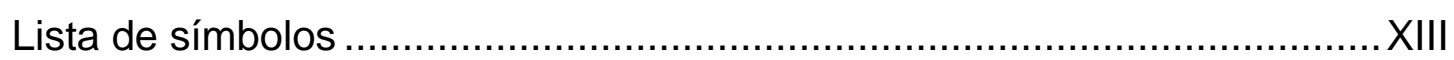

Lista de abreviatura dos aminoácidos .................................................. XIV

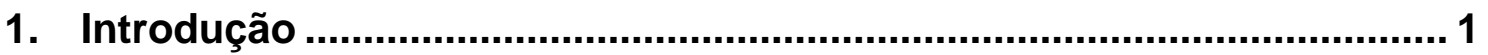

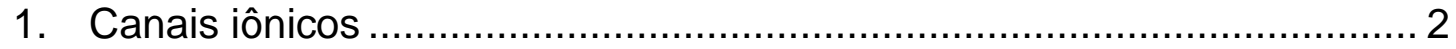

1.1. Canais iônicos dependentes de voltagem .......................................... 3

1.1.1. Descoberta dos canais voltagem - dependentes ......................... 3

1.1.2. Estrutura dos canais voltagem - dependentes............................. 6

1.1.3. Teoria evolutiva dos canais voltagem - dependentes ................... 9

1.1.4. Fisiologia dos canais voltagem - dependentes .......................... 10

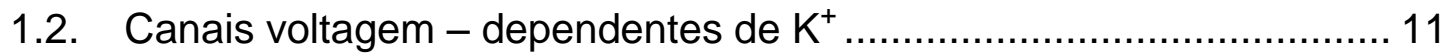

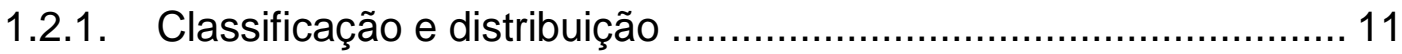

1.2.2. Cinética de ativação e inativação e seletividade iônica ................. 15

1.2.3. Farmacologia e Importância médica ("Canalopatias") .................. 27

1.3. Canais voltagem - dependentes de $\mathrm{K}^{+}$são alvos biológicos de

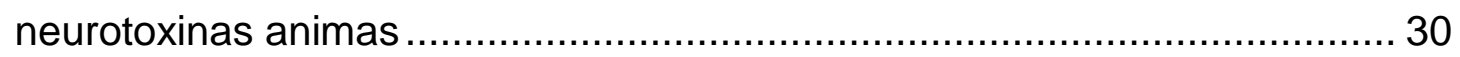

1.4. Anêmonas do mar - Aspectos ecológicos, fisiológicos e evolutivos ... 31

1.5. Composição do veneno das anêmonas do mar ................................. 32

1.5.1. Neurotoxinas - Importância, seletividade e mecanismos de ação 33

1.5.2. Toxinas que atuam em canais voltagem - dependentes de $\mathrm{K}^{+} \ldots .34$

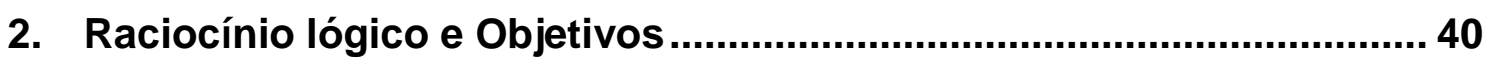

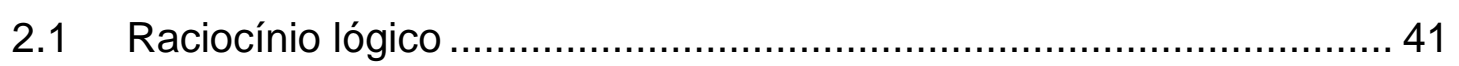

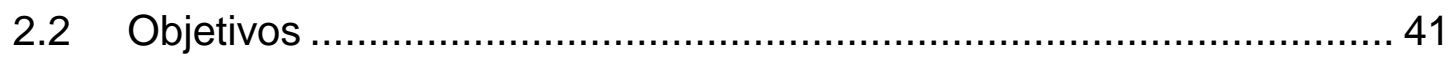

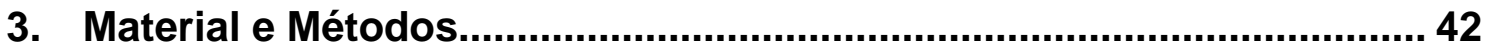

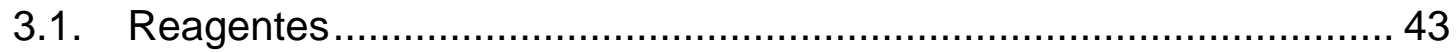

3.2. Captura e identificação das espécies de anêmonas do mar ................ 43

3.3. Extração das Peçonhas ............................................................... 43

3.4. Determinação do conteúdo protéico................................................ 44

3.5. Fracionamento e Purificação das Peçonhas ....................................... 44 
3.6. Determinação da massa molecular .................................................. 46

3.7. Determinação do padrão de pontes dissulfeto ................................... 46

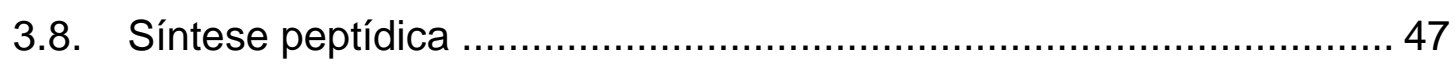

3.9. Medidas eletrofisiológicas em ovócitos de Xenopus laevis - Técnica de

"Voltage clamp" com dois microeletrodos. ................................................ 48

3.9.1. Isolamento e preparação dos ovócitos. ........................................ 48

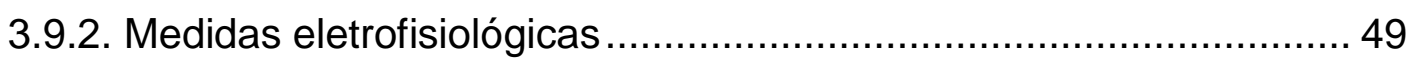

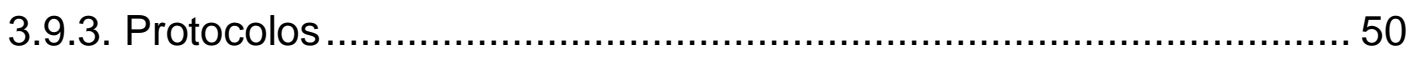

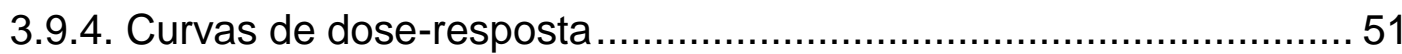

3.9.5. Curvas de corrente em função da voltagem ................................ 52

3.9.6. Determinação da reversibilidade da ligação das neurotoxinas ........ 52

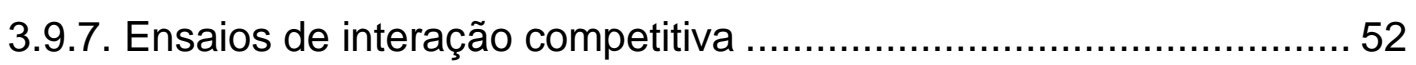

3.9.8. Dependência da conformação estrutural do canal para ligação

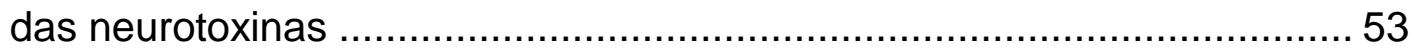

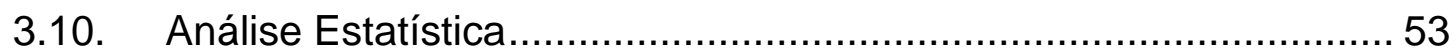

3.11. Determinação da sequência de aminoácidos das neurotoxinas .......53

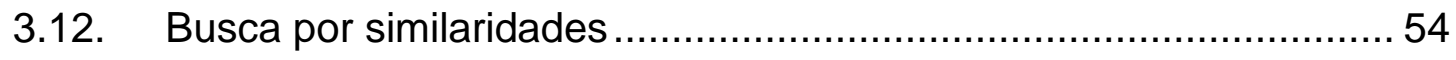

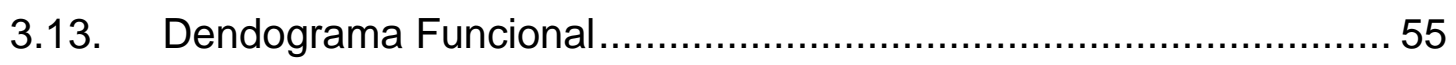

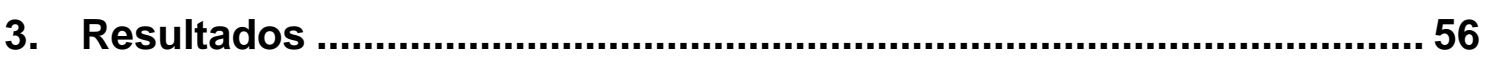

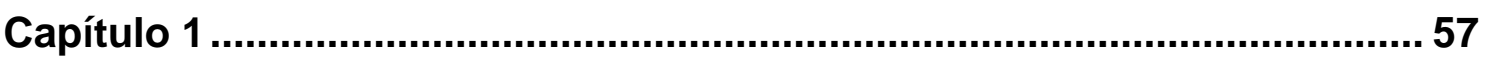

A novel type of $\mathrm{K}^{+}$- channel toxin from the sea anemones Actinia bermudensis and Bunodosoma caissarum: AbeTx1 and BcsTx4 are the first members of a new subfamily of kappa-toxins. ......................................... 57

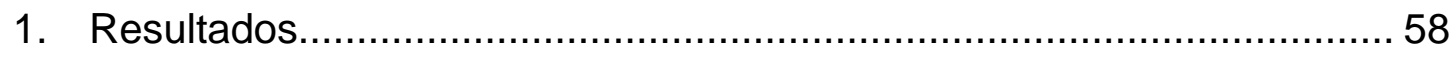

1.1. Purificação e caracterização bioquímica das neurotoxinas AbeTx1 e

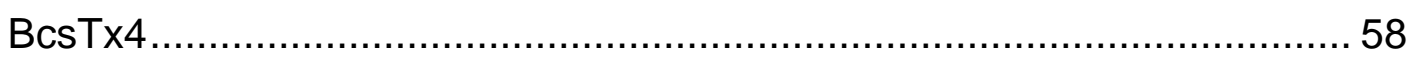

1.2. Determinação da sequência de aminoácidos e do padrão de pontes dissulfeto dos peptídeos AbeTx1 e BcsTx4 …………............................ 62

1.3. Perfil farmacológico da neurotoxina AbeTx1 ................................. 64

1.4. Ensaios para determinação da relação entre a estrutura e função da

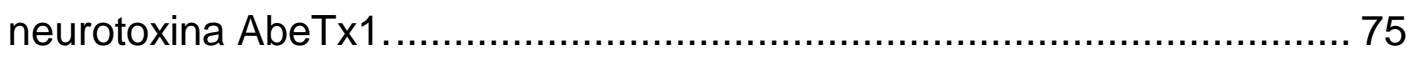

1.5. Perfil farmacológico da neurotoxina BcsTx4 …............................. 78

1.6. Análise da estrutura primária das neurotoxinas AbeTx1 e BcsTx4.. 85

2. Discussão. 88 
2.1. Obtenção das peçonhas das anêmonas do mar A. bermudensis e B.

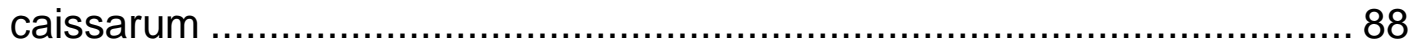

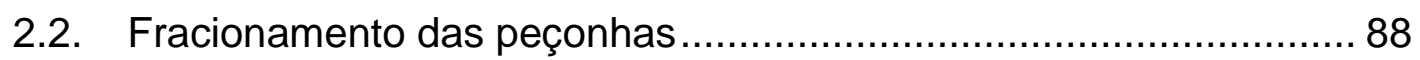

2.3. Purificação das neurotoxinas AbeTx1 e BcsTx4 …......................... 89

2.4. Potência e seletividade das neurotoxinas AbeTx1 e BcsTx4 ........... 89

2.5. Interação da AbeTx1 e da BcsTx4 com o subtipo de $K_{v} 1.1 \ldots \ldots \ldots . . . .92$

2.6. Interação da AbeTx1 e BcsTx4 com os subtipos de $\mathrm{K}_{v} 1.2$ e $\mathrm{K}_{\mathrm{v}} 1.6 .97$

2.7. Relação entre a estrutura da AbeTx1 e o bloqueio da corrente dos

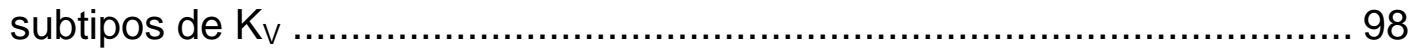

2.8. Análise comparativa e evolutiva da AbeTx1 e BcsTx4 ................. 100

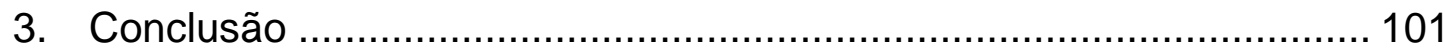

Capítulo 2

Biochemical and electrophysiological characterization of two sea anemone Type 1 potassium toxins from a geographically distant population of

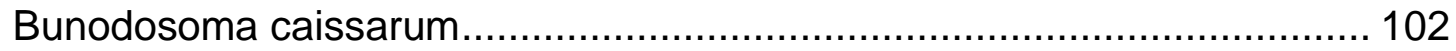

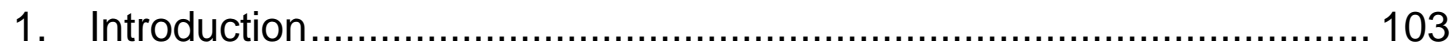

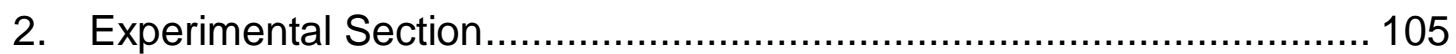

2.1. Sea anemone Collection, Venom Isolation and Neurotoxins

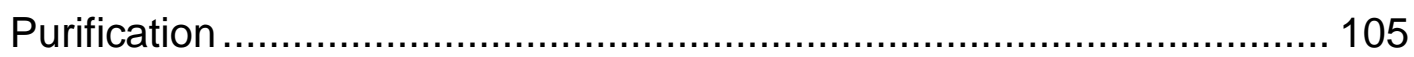

2.2. Mass Spectrometry Analysis ................................................... 106

2.3. Amino acid sequence determination .......................................... 106

2.4. Expression of voltage-gated ion channels in Xenopus laevis oocytes 106

2.5. Phylogenetic Analysis and Sequence Alignment ........................ 108

2.6. Structure Computational Modeling ........................................... 108

2.7. Statistical Assessment ............................................................. 109

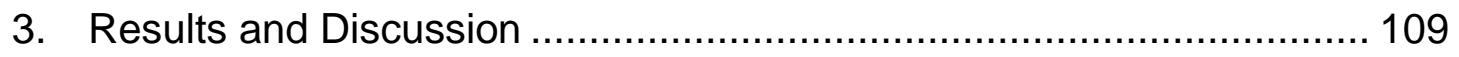

3.1. Venom Purification and Biochemical Characterization of BcsTx1 and

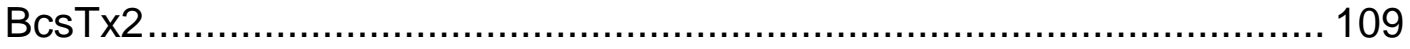

3.2. Amino Acid Sequences and Phylogenetic Analysis ...................... 114

3.3. BcsTx1 and BcsTx2 Pharmacological Profiles ............................ 118

3.4. Bioinformatics Analysis ....................................................... 126

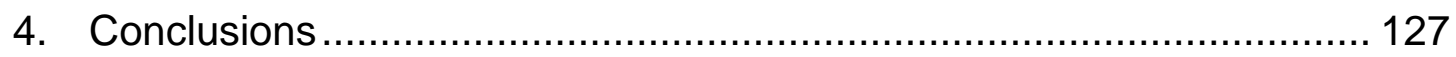

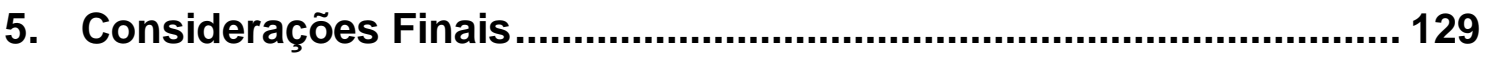




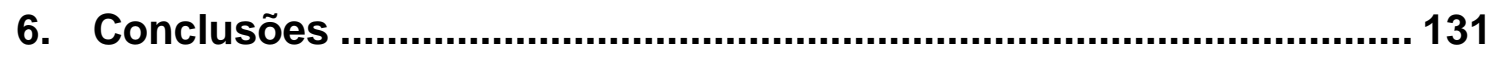

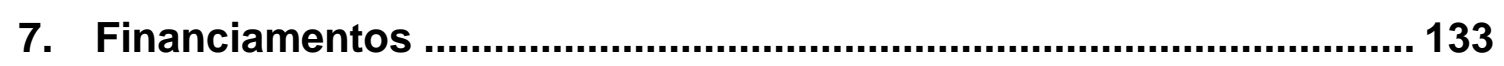

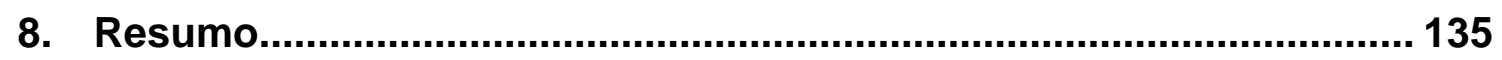

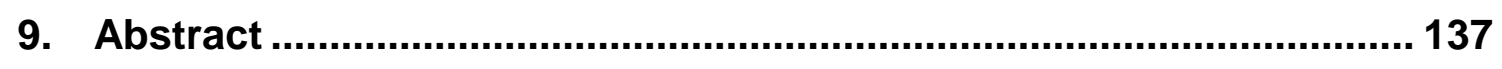

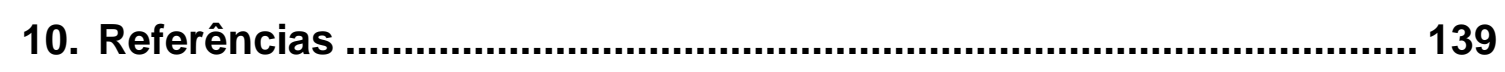




\section{Lista de Figuras}

FIGURA 1 - SUPERFAMÍLIA DE CANAIS IÔNICOS. O DENDOGRAMA REPRESENTA 143 MEMBROS DAS DIFERENTES FAMÍLIAS DE CANAIS IÔNICOS. OS RAMOS EM AZUL SÃO REPRESENTADOS PELOS CANAIS VOLTAGEM - DEPENDENTES DE NA ${ }^{+} E$ $\mathrm{CA}^{2+}$. OS RAMOS VERMELHOS INDICAM OS CANAIS SELETIVOS PARA OS ÍONS $\mathrm{K}^{+}$. EM MAGENTA ESTÃO OS CANAIS ATIVADOS POR NUCLEOTÍDEOS CÍCLICOS E EM VERDE TEM-SE OS DIFERENTES "TRANSIENT RECEPTOR POTENTIAL". FIGURA MODIFICADA DE CATTERALL E COLABORADORES (CATTERALL ET AL, 2005).

FIGURA 2 - ESTRUTURA DOS CANAIS VOLTAGEM - DEPENDENTES DE NA ${ }^{+}, \mathrm{CA}^{2+} \mathrm{E} \mathrm{K}^{+}$. OS CANAIS VOLTAGEM - DEPENDENTES DE NA $\mathrm{NA}^{+} \mathrm{CA}^{2+}$ SÃO FORMADOS POR UMA ÚNICA CADEIA POLIPEPTÍDICA COM QUATRO DOMÍNIOS (I - IV), CADA QUAL CONTENDO SEIS SEGMENTOS TRANSMEMBRANA. O CANAL VOLTAGEM DEPENDENTE DE $\mathrm{K}^{+}\left(\mathrm{K}_{\mathrm{V}}\right)$ É FORMADO POR QUATRO SUBUNIDADES, CADA QUAL CONTENDO SEIS SEGMENTOS TRANSMEMBRANA. ASSIM COMO OS CANAIS VOLTAGEM - DEPENDENTES DE NA ${ }^{+} \mathrm{E} \mathrm{CA}^{2+}$, O KV PODE ESTAR ASSOCIADO A SUBUNIDADES AUXILIARES (B SUBUNIDADE OU KCHIP). FIGURA MODIFICADA DE (LAI \& JAN, 2006).

FIGURA 3 - CLASSIFICAÇÃO DOS CANAIS SELETIVOS PARA O ÍON K+. A - CANAIS 'INWARDLY RECTIFYING', COM DOIS SEGMENTOS TRANSMEMBRANA (KIR). B CANAIS COM DOIS POROS E QUATRO SEGMENTOS TRANSMEMBRANARES (K2P OU "LEAK CHANNELS"), C - CANAIS COM OITO SEGMENTOS TRANSMEMBRANARES E DOIS POROS. D - CANAIS COM SEIS SEGMENTOS TRANSMEMBRANARES QUE PODEM SER ATIVADOS POR $\mathrm{CA}^{2+}\left(\mathrm{K}_{\mathrm{CA}}\right)$ OU DEPENDENTES DE VOLTAGEM $\left(\mathrm{K}_{\mathrm{V}}\right)$. E - SUBDIVISÃO DOS CANAIS COM SEIS SEGMENTOS TRANSMEMBRANA EM CINCO FAMÍLIAS: KV, EAG, KQT, SK E SLO. AS FAMÍLIAS SK E SLO SÃO FORMADAS POR CANAIS ATIVADOS POR $\mathrm{CA}^{2+}$, AO PASSO QUE AS FAMÍLIAS $K_{V}$, EAG E KQT SÃO FORMADAS POR CANAIS VOLTAGEM DEPENDENTES (SUBFAMÍLIAS DE $\mathrm{K}_{\mathrm{v}} 1-\mathrm{K}_{\mathrm{v}} 12$ ). FIGURA MODIFICADA DE (CHOE, 2002; COETZEE ET AL, 1999)

FIGURA 4 - LOCALIZAÇÃO DO SENSOR DE VOLTAGEM. A - MODELO ILUSTRATIVO DA LOCALIZAÇÃO E DESLOCAMENTO DO SEGMENTO S4 DO CANAL KVAP. O SEGMENTO S4 SE ENCONTRA NA INTERFACE ENTRE O CITOPLASMA E A MEMBRANA PLASMÁTICA E É CAPAZ DE SE DESLOCAR MAIS DE 15 Å AO LONGO DA MEMBRANA PLASMÁTICA, DURANTE SUA DESPOLARIZAÇÃO (JIANG ET AL, 
2003B). B - MODELO ILUSTRATIVO PROPOSTO PARA A LOCALIZAÇÃO DO SEGMENTO S4 DO KV1.2, O QUAL ESTÁ DISPOSTO PARALELAMENTE À MEMBRANA PLASMÁTICA (LONG ET AL, 2005B). C - MODELO ATUALMENTE ACEITO PARA O DESLOCAMENTO DO SEGMENTO S4 DURANTE A DESPOLARIZAÇÃO DA MEMBRANA PLASMÁTICA. QUANDO A VOLTAGEM DA MEMBRANA FOR MENOR NEGATIVA $\left(\mathrm{V}_{\mathrm{M}}<0\right)$, O CANAL SE ENCONTRA NO ESTADO FECHADO E AS "GATING CHARGES" ENCONTRAM-SE PRÓXIMAS AO MEIO INTRACELULAR. QUANDO OCORRE A DESPOLARIZAÇÃO DA MEMBRANA, O SEGMENTO S4 DESLOCA-SE EM DIREÇÃO AO MEIO EXTRACELULAR. FIGURA MODIFICADA DE (CHANDA ET AL, 2005; CHOE, 2002; DRYGA ET AL, 2012).

FIGURA 5 - MECANISMO DE ATIVAÇÃO DO KV. A - REPRESENTAÇÃO ESQUEMÁTICA DO CANAL NO ESTADO FECHADO. SEGMENTO S4 ENCONTRA-SE PRÓXIMO AO MEIO INTRACELULAR E OS SEGMENTOS S6 ESTÃO PRÓXIMOS UNS AOS OUTROS. B - REPRESENTAÇÃO DO CANAL NO ESTADO ABERTO. O SEGMENTO S4 DESLOCA-SE PARA O MEIO EXTRACELULAR E O SEGMENTO S5 E S6 SOFREM ALTERAÇÕES DE CONFORMAÇÃO ESTRUTURAL QUE PERMITEM A PASSAGEM DOS ÍONS $\mathrm{K}^{+}$. C - COMPROVAÇÃO DO MECANISMO DE ATIVAÇÃO DO KV. O SÍTIO DE LIGAÇÃO DO TEA, 4-AP E O ÍON CD $^{2+}$ SOMENTE ESTA ACESSÍVEL QUANDO O CANAL SE ENCONTRA NO ESTADO ABERTO. FIGURA MODIFICADA DE (ARMSTRONG, 2003).

FIGURA 6 - MECANISMOS DE INATIVAÇÃO DO KV. APÓS A ABERTURA DO CANAL, ESTE PODE INATIVAR-SE POR INTERMÉDIO DE TRÊS MECANISMOS DISTINTOS: "BALLAND-CHAIN", "C-TYPE” E "S6 GATE'. FIGURA MODIFICADA DE (YELLEN, 2002).

FIGURA 7 - PROPRIEDADES FÍSICO-QUÍMICAS ENVOLVIDAS NA SELETIVIDADE IÔNICA. A - ESTRUTURA DE UMA SUBUNIDADE DE UM CANAL VOLTAGEM - DEPENDENTE DE K', APRESENTANDO O "DOMÍNIO SENSOR DE VOLTAGEM" E O "DOMÍNIO DO PORO". B - TOPOLOGIA DO "DOMÍNIO DO PORO" DO CANAL, ONDE 1 INDICA A REGIÃO EXTRACELULAR; 2, FILTRO DE SELETIVIDADE; 3, CÂMARA INTERNA CONTENDO ÁGUA E AMINOÁCIDOS HIDROFÓBICOS; 4, PORO HIDROFÓBICO PARA DESIDRATAÇÃO DOS ÍONS $\mathrm{K}^{+}$; 5, REGIÃO DO CANAL EXPOSTA AO MEIO INTRACELULAR. C - REPRESENTAÇÃO DO FILTRO DE SELETIVIDADE COM OS SEIS SÍTIOS DE LIGAÇÃO PARA O ÍON K+. D - ILUSTRAÇÃO DA SOLVATAÇÃO DOS ÍONS $\mathrm{NA}^{+} E \mathrm{~K}^{+} \mathrm{E}$ QUANDO ESTÃO EM CONTATO COM OS GRUPOS CARBONILA DOS AMINOÁCIDOS DO FILTRO DE SELETIVIDADE. FIGURA MODIFICADA DE (ALLEN ET AL, 2000; ARMSTRONG, 2003; CHOE, 2002; YELLEN, 2002) 
FIGURA 8 - ISOLAMENTO E PREPARAÇÃO DOS OVÓCITOS DE XENOPUS LAEVIS. A EXEMPLAR DO XENOPUS LAEVIS. B - OVARIOTECTOMIA PARCIAL PARA A RETIRADA DOS OVÓCITOS. C - SELEÇÃO DOS OVÓCITOS. D - INJEÇÃO DO CRNA DOS CANAIS VOLTAGEM DEPENDENTES DE $\mathrm{K}^{+} E \mathrm{NA}^{+}$NOS OVÓCITOS. FOTOS CEDIDAS POR EVA CUYPERS, DO "LABORATORY OF TOXICOLOGY" DA K.U.LEUVEN, BÉLGICA.

FIGURA 9 - PROTOCOLOS DE PULSOS DE VOLTAGEM UTILIZADOS PARA OS REGISTROS DAS CORRENTES DOS CANAIS VOLTAGEM - DEPENDENTES DE K ${ }^{+} E$ $\mathrm{NA}^{+}$, EXPRESSOS EM OVÓCITOS DE X. LAEVIS. A - PROTOCOLO UTILIZADO PARA AS ISOFORMAS $\mathrm{K}_{\mathrm{v}} 1.1-6, \mathrm{~K}_{\mathrm{v}} 2.1 \mathrm{E}$ SHAKER IR. B - PROTOCOLO UTILIZADO PARA ISOFORMA $K_{v}$ 3.1, $K_{v} 4,2$ E $K_{v} 4.3$. C - PROTOCOLO UTILIZADO PARA ISOFORMA HERG. D - PROTOCOLO UTILIZADO PARA ISOFORMAS NA $1.2, N A_{v} 1.4$ E BGNA.

FIGURA 10 - FRACIONAMENTO E PURIFICAÇÃO DA PEÇONHA DAS ANÊMONAS $A$. BERMUDENSIS E B. CAISSARUM. A - PERFIL CROMATOGRÁFICO DA FILTRAÇÃO EM GEL DA PEÇONHA DE A. BERMUDENSIS. COLUNA: SEPHADEX G-50 (2,5 X 120CM), EQUILIBRADA E ELUÍDA COM TAMPÃO ACETATO DE AMÔNIO 100 MM PH 6,5. FLUXO DE 2 ML/MIN. A ELUIÇÃO DA PEÇONHA FOI MONITORADA PELA ABSORBÂNCIA A 280NM. AS ABREVIAÇÕES I A V CORRESPONDEM ÀS FRAÇÕES AGRUPADAS, QUE POSTERIORMENTE PASSARÃO A SEREM DENOMINADAS ABE I A V. B - PERFIL DA PRIMEIRA ETAPA CROMATOGRÁFICA DA FASE REVERSA (RPHPLC) DA FRAÇÃO ABE III (2 MG) PROVENIENTE DA GEL-FILTRAÇÃO. O NÚMERO 1 INDICA O PICO QUE FOI SUBMETIDO À SEGUNDA ETAPA CROMATOGRÁFICA. COLUNA: CAPCELL PAK C-18 (1,0 X 25 CM) EQUILIBRADA COM SOLUÇÃO A. OS PEPTÍDEOS FORAM ELUÍDOS COM GRADIENTE LINEAR DA SOLUÇÃO B (10 A $50 \%$ EM 35 MINUTOS). FLUXO: 2,5 ML/MIN. A ELUIÇÃO DOS PEPTÍDEOS FOI MONITORADA PELA ABSORBÂNCIA A 214NM. C - PERFIL DA SEGUNDA ETAPA CROMATOGRÁFICA DA FASE REVERSA (HPLC). PICO MAJORITÁRIO REPRESENTA O PEPTÍDEO ABETX1. COLUNA: CAPCELL PAK C-18 (0,46 X 25 CM) EQUILIBRADA COM SOLUÇÃO A. OS PEPTÍDEOS FORAM ELUÍDOS NO MODO ISOCRÁTICO DA SOLUÇÃO B (9\%). FLUXO: 1,0ML/MIN. D - PERFIL CROMATOGRÁFICO DA FILTRAÇÃO EM GEL DA PEÇONHA DE B. CAISSARUM. E - PERFIL DA PRIMEIRA ETAPA CROMATOGRÁFICA DA FASE REVERSA (RP-HPLC) DA FRAÇÃO III PROVENIENTE DA GEL-FILTRAÇÃO. $F$ - PERFIL DA SEGUNDA ETAPA CROMATOGRÁFICA DE FASE REVERSA (HPLC). OS PEPTÍDEOS FORAM ELUÍDOS NO MODO ISOCRÁTICO DA SOLUÇÃO B (9\%). FLUXO: 1,0ML/MIN. PICO MAJORITÁRIO REPRESENTA O PEPTÍDEO BCSTX4. 
FIGURA 11 - DETERMINAÇÃO DA PUREZA DOS PEPTÍDEOS ABETX1 E BCSTX4. A ESPECTRO DE MASSA DO PEPTÍDEO ABETX1 (M/Z 1889,8 DALTONS). B ESPECTRO DE MASSA DO PEPTÍDEO BCSTX4 (M/Z 1830,7 DA).

FIGURA 12 - DETERMINAÇÃO DO PADRÃO DE PONTES DISSULFETO DO PEPTÍDEO ABETX1. A - FRAGMENTO DE M/Z IGUAL A 716,3 DA, CORRESPONDENTE À SEQUÊNCIA RCKPNC. B - FRAGMENTO DIGERIDO COM M/Z DE 1151,6 DA, REFERENTE À SEQUÊNCIA TCSKGRCRPK.

FIGURA 13 - DETERMINAÇÃO DO PADRÃO DE PONTES DISSULFETO DO PEPTÍDEO BCSTX4. O VALOR DE M/Z IGUAL A 1191,6 DA CORRESPONDE AO FRAGMENTO DE AMINOÁCIDOS ECVKGRCRPK DA SEQUÊNCIA DO PEPTÍDEO BCSTX4. COMPROVANDO QUE A SEGUNDA E TERCEIRA CISTEÍNAS FORMAM UMA PONTE DISSULFETO.

FIGURA 14 - EFEITO INIBITÓRIO DA TOXINA ABETX1 NOS DIFERENTES SUBTIPOS DE $K_{V}$. OS PERFIS REPRESENTAM A SITUAÇÃO CONTROLE E QUANDO APLICADOS 3 $\mu M$ DA TOXINA ABETX1. O * REPRESENTA O BLOQUEIO OU NÃO DA CORRENTE APÓS A APLICAÇÃO DE $3 \mu \mathrm{M}$ DA TOXINA ABETX1. A LINHA TRACEJADA INDICA O NÍVEL BASAL DE CORRENTE $(\mathrm{N}=6)$.

FIGURA 15 - EFEITO INIBITÓRIO DA TOXINA ABETX1 NOS DIFERENTES SUBTIPOS DE NA. OS PERFIS REPRESENTAM A SITUAÇÃO CONTROLE E QUANDO APLICADOS $3 \mu \mathrm{M}$ DA TOXINA ABETX1. O * REPRESENTA O BLOQUEIO OU NÃO DA CORRENTE APÓS A APLICAÇÃO DE $3 \mu \mathrm{M}$ DA TOXINA ABETX1. A LINHA TRACEJADA INDICA O NÍVEL BASAL DE CORRENTE $(\mathrm{N}=3)$.

FIGURA 16 - ENSAIOS ELETROFISIOLÓGICOS EM $\mathrm{K}_{\mathrm{v}} 1.1$, UTILIZANDO-SE A NEUROTOXINA ABETX1. A - CURVA DOSE-RESPOSTA DA TOXINA ABETX1, VALOR DE IC ${ }_{50}$ É DE 671,95 \pm 150,31 NM (N=6). B - CURVA DE CORRENTE $X$ VOLTAGEM NA AUSÊNCIA E PRESENÇA DE ABETX1 (600 NM). A CURVA COM OS PONTOS QUADRADOS (PRETOS) É O CONTROLE E A CURVA COM PONTOS CIRCULARES (VERMELHO) É NA PRESENÇA DA TOXINA (N=6). C - CURVA DE DEPENDÊNCIA DE VOLTAGEM DO BLOQUEIO DA TOXINA ABETX1 (600 NM) (N=6). D - CURVA DE CORRENTE $X$ VOLTAGEM NA AUSÊNCIA E PRESENÇA DE ABETX1 (450 NM) EM SOLUÇÃO ND96 COM ALTA CONCENTRAÇÃO DE ÍONS K' (HK-ND96). A CURVA COM OS PONTOS QUADRADOS (PRETOS) É O CONTROLE E A CURVA COM PONTOS CIRCULARES (VERMELHO) É NA PRESENÇA DA TOXINA ABETX1 (450 NM) $(\mathrm{N}=5)$. E - ENSAIO DE REVERSIBILIDADE DA LIGAÇÃO DA ABETX1 (3 $\mu \mathrm{M})$. F - 
ENSAIO DE INTERAÇÃO COMPETITIVA ENTRE ABETX1 (600 NM) E TEA (200 $\mu \mathrm{M})$ $(\mathrm{N}=5)$.

FIGURA 17 - EFEITO INIBITÓRIO DA ABETX1 NA CORRENTE DOS ÍONS K+ EM KV1.1. A PROTOCOLO DE ATIVAÇÃO DO KV1.1. B - CURVA CONTROLE DE ATIVAÇÃO DO $K_{v} 1.1$, ANTES DA APLICAÇÃO DA TOXINA. C - CURVA DE ATIVAÇÃO DO K $K_{v} 1.1$, APÓS A HOMOGENEIZAÇÃO DA ABETX1 NA SOLUÇÃO E O REPOUSO DE DOIS MINUTOS. ABETX1 BLOQUEOU 82,00 $\pm 2,65 \%$ DA CORRENTE DO $K_{v} 1.1(\mathrm{~N}=4)$.

FIGURA 18 - ENSAIOS ELETROFISIOLÓGICOS EM $K_{V}$ 1.2, UTILIZANDO-SE A NEUROTOXINA ABETX1. A - CURVA DOSE-RESPOSTA DA TOXINA ABETX1, O VALOR DE IC 50 É DE $167,36 \pm 38,58 \mathrm{NM}(\mathrm{N}=6)$. B - CURVA DE CORRENTE $X$ VOLTAGEM NA AUSÊNCIA E PRESENÇA DE ABETX1 (160 NM). A CURVA COM OS PONTOS QUADRADOS (PRETOS) É O CONTROLE E A CURVA COM PONTOS CIRCULARES (VERMELHO) É NA PRESENÇA DA TOXINA ( $N=3)$. C - CURVA DE DEPENDÊNCIA DE VOLTAGEM DO BLOQUEIO DA TOXINA ABETX1 (160 NM) (N=3). D - CURVA DE CORRENTE $X$ VOLTAGEM NA AUSÊNCIA E PRESENÇA DE ABETX1 (160 NM), EM SOLUÇÃO COM ALTA CONCENTRAÇÃO DE ÍONS K' (HK-ND96). A CURVA COM OS PONTOS QUADRADOS (PRETOS) É O CONTROLE E A CURVA COM PONTOS CIRCULARES (VERMELHO) É NA PRESENÇA DA TOXINA (N=3). E ENSAIO DE REVERSIBILIDADE DA LIGAÇÃO DA ABETX1 $(3 \mu \mathrm{M})$.

FIGURA 19 - ENSAIOS ELETROFISIOLÓGICOS EM Kv 1.6. A - CURVA DOSE-RESPOSTA DA TOXINA ABETX1, O VALOR DE IC $5_{50}$ É DE 115,68 $\pm 31,44 \mathrm{NM}(\mathrm{N}=6)$. B - CURVA DE CORRENTE $X$ VOLTAGEM NA AUSÊNCIA E PRESENÇA DE ABETX1 (120 NM). A CURVA COM OS PONTOS QUADRADOS (PRETOS) É O CONTROLE E A CURVA COM PONTOS CIRCULARES (VERMELHO) É NA PRESENÇA DA TOXINA ( $N=3$ ). C CURVA DE DEPENDÊNCIA DE VOLTAGEM DO BLOQUEIO DA TOXINA ABETX1 (120 NM) $(N=3)$. D - CURVA DE CORRENTE $X$ VOLTAGEM NA AUSÊNCIA E PRESENÇA DE ABETX1 (70 NM) EM SOLUÇÃO COM ALTA CONCENTRAÇÃO DE ÍONS K ${ }^{+}$(HKND96). A CURVA COM OS PONTOS QUADRADOS (PRETOS) É O CONTROLE E A CURVA COM PONTOS CIRCULARES (VERMELHO) É NA PRESENÇA DA TOXINA ( $\mathrm{N}=$ 3). E - ENSAIO DE REVERSIBILIDADE DA LIGAÇÃO DA ABETX1 (3 $\mu \mathrm{M})$. F - ENSAIO DE INTERAÇÃO COMPETITIVA ENTRE AS TOXINAS ABETX1 (600 NM) E TEA (920 $\mu \mathrm{M})(\mathrm{N}=5)$

FIGURA 20 - ENSAIOS ELETROFISIOLÓGICOS REALIZADOS EM $\mathrm{K}_{v} 1.1, \mathrm{~K}_{\mathrm{v}} 1.2$ E $\mathrm{K}_{\mathrm{v}} 1.6$, UTILIZANDO-SE OS SEIS MUTANTES DA TOXINA ABETX1. A - CURVAS DE DOSERESPOSTA DOS MUTANTES ABETX1 - R1A, K3A, K7A, R9A, R11A E K13A NO SUBTIPO DE $K_{V}$ 1.1. B - PORCENTAGEM DE INIBIÇÃO DA CORRENTE DOS ÍONS $\mathrm{K}^{+}$ 
DO SUBTIPO DE KV 1.2 QUANDO APLICADOS OS MUTANTES DA ABETX1 (30 $\mu \mathrm{M})$. C - CURVAS DE DOSE-RESPOSTA DOS SEIS MUTANTES DA TOXINA ABETX1 NO SUBTIPO DE Kv1.6.

FIGURA 21 - EFEITO INIBITÓRIO DA TOXINA BCSTX4 NOS DIFERENTES SUBTIPOS DE KV. OS PERFIS REPRESENTAM A SITUAÇÃO CONTROLE E QUANDO APLICADOS 3 $\mu M$ DA TOXINA BCSTX4. O * REPRESENTA O BLOQUEIO OU NÃO DA CORRENTE APÓS A APLICAÇÃO DE $3 \mu \mathrm{M}$ DA TOXINA ABETX1. A LINHA TRACEJADA INDICA O NÍVEL BASAL DE CORRENTE $(\mathrm{N}=6)$.

FIGURA 22 - EFEITO INIBITÓRIO DA TOXINA BCSTX4 NOS DIFERENTES SUBTIPOS DE NA ${ }_{v}$. OS PERFIS REPRESENTAM A SITUAÇÃO CONTROLE E QUANDO APLICADOS $3 \mu \mathrm{M}$ DA TOXINA BCSTX4. O * REPRESENTA O BLOQUEIO OU NÃO DA CORRENTE APÓS A APLICAÇÃO DE $3 \mu \mathrm{M}$ DA TOXINA BCSTX4. A LINHA TRACEJADA INDICA O NÍVEL BASAL DE CORRENTE $(\mathrm{N}=3)$.

FIGURA 23 - ENSAIOS ELETROFISIOLÓGICOS COM A NEUROTOXINA BCSTX4 NO SUBTIPO DE $K_{V}$ 1.1. A - CURVA DOSE-RESPOSTA DA TOXINA BCSTX4, O VALOR DE $I_{50}$ É DE 1267,72 $\pm 77,83$ NM (N=6). B - CURVA DE CORRENTE $X$ VOLTAGEM NA AUSÊNCIA E PRESENÇA DE BCSTX4 (1200 NM). A CURVA COM OS PONTOS QUADRADOS (PRETOS) É O CONTROLE E A CURVA COM PONTOS CIRCULARES (VERMELHO) É NA PRESENÇA DA TOXINA (N=3). C - CURVA DE DEPENDÊNCIA DE VOLTAGEM DO BLOQUEIO DA TOXINA BCSTX4 (1200 NM) (N=3). D - ENSAIO DE

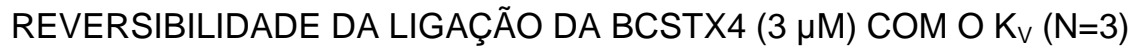

FIGURA 24 - ENSAIOS ELETROFISIOLÓGICOS COM A NEUROTOXINA BCSTX4 NO SUBTIPO DE KV1.6. A - CURVA DOSE-RESPOSTA DA TOXINA ABETX1, O VALOR DE $I_{50}$ É DE 226,10 $\pm 76,39 \mathrm{NM}(\mathrm{N}=6)$. B - CURVA DE CORRENTE $X$ VOLTAGEM NA AUSÊNCIA E NA PRESENÇA DE BCSTX4 (270 NM). A CURVA COM OS PONTOS QUADRADOS (PRETOS) É O CONTROLE E A CURVA COM PONTOS CIRCULARES (VERMELHO) É NA PRESENÇA DA TOXINA (N=3). C - CURVA DE DEPENDÊNCIA DE VOLTAGEM DO BLOQUEIO DA TOXINA BCSTX4 (270 NM) (N=3). D - ENSAIO DE REVERSIBILIDADE DA LIGAÇÃO DA ABETX1 (3 $\mu \mathrm{M})$. E - ENSAIO DE INTERAÇÃO COMPETITIVA ENTRE AS TOXINAS ABETX1 (120 NM) E BCSTX4 $(250 \mu \mathrm{M})(\mathrm{N}=5)$.

FIGURA 25 - DENDOGRAMA FUNCIONAL CONSTRUÍDO A PARTIR DO ALINHAMENTO DAS SEQUÊNCIAS DAS "KAPPA-TOXINAS" DA TABELA 4. DESCRIÇÃO DAS SETE SUBFAMÍLIAS DE KAPPA-TOXINAS (K-KTX1 - K-KTX7). ABETX1 E BCSTX4 SÃO OS PRIMEIROS MEMBROS DE UMA NOVA SUBFAMÍLIA DE "KAPPA-TOXINAS". 
FIGURA 26 - ALINHAMENTO DAS SEQUÊNCIAS DE AMINOÁCIDOS DA ABETX1 E BCSTX4. AMINOÁCIDOS GRIFADOS EM PRETO SÃO IDÊNTICOS. AMINOÁCIDOS NÃO GRIFADOS POSSUEM CARACTERÍSTICAS FÍSICO-QUÍMICAS DISTINTAS.

FIGURE 27 - MAP SHOWING THE GEOGRAPHIC LOCALIZATION OF THE COLLECTION SITES OF B. CAISSARUM POPULATIONS USED IN THIS STUDY. THE RED CIRCLE INDICATES SAINT PETER AND SAINT PAUL ARCHIPELAGO (SPSPA) LOCATION AT

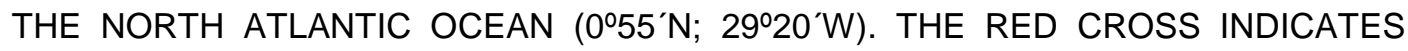
SOUTHEAST COAST OF BRAZIL (SÃO SEBASTIÃO BEACH - S2356', W4520'), MORE THAN 4,000 KM DISTANT FROM THE SPSPA.

FIGURE 28 - ISOLATION, PURIFICATION AND CHARACTERIZATION OF B. CAISSARUM VENOM. (A) GEL-FILTRATION CHROMATOGRAPHY OF B. CAISSARUM VENOM. APPROXIMATELY 3.0 G OF VENOM WAS INJECTED INTO A SEPHADEX G-50 COLUMN AND THE FRACTIONS WERE ELUTED WITH 0.1 M AMMONIUM ACETATE BUFFER (PH 7.0). FRACTIONS I TO V WERE COLLECTED DURING UV (280 NM) MONITORING. (B) RP-HPLC CHROMATOGRAM OF FRACTION III RESULTING FROM GEL-FILTRATION. THE PEPTIDESFROM FRIII WERE ELUTED AS DESCRIBED UNDER 'EXPERIMENTAL SECTION'. PEAKS LABELED (1 AND 2) WERE SUBJECTED TO A SECOND C18 RP-HPLC CHROMATOGRAPHY. (C) PEAK 1 (BCSTX1) WAS PURIFIED ON AN ANALYTICAL C18 COLUMN USING AN ISOCRATIC CONDITION OF $13 \%$ OF ACETONITRILE CONTAINING $0.1 \%$ TFA. (D) PURIFICATION OF PEAK 2 (BCSTX2) USING AN ISOCRATIC CONDITION OF 16\% OF ACETONITRILE CONTAINING $0.1 \%$ TFA. (E) MASS MEASUREMENT OF PURIFIED BCSTX1 DETERMINED BY MALDI-TOF, INDICATING A M/Z OF 2075,955 ( $Z=2)$ AND 4151.91 (Z =1). (F) MASS SPECTROMETRY PROFILE OF PURIFIED BCSTX2 (M/Z3914.521).

FIGURE 29 - COMPARISON OF THE 'NEUROTOXIC FRACTION' (FRIII) FROM TWO POPULATIONS OF THE SEA ANEMONE B. CAISSARUM: SOUTHEASTERN COAST OF BRAZIL AND SAINT PETER AND SAINT PAUL ARCHIPELAGO. THE BLACK CONTINUOUS LINE REPRESENTS THE RP-HPLC PROFILE OF FRIII FROM THE SOUTHEASTERN COAST POPULATION. LABELED PEAKS WERE THE PREVIOUSLY CHARACTERIZED NEUROTOXINS BCIII (OLIVEIRA ET AL, 2004) AND BCIV (OLIVEIRA ET AL, 2006). RED DOTTED LINE IS THE FRIII CHROMATOGRAPHIC PROFILE OF THE SPSPA POPULATION. 'NEUROTOXIC FRACTIONS' WERE SUBMITTED TO RP-HPLC CHROMATOGRAPHY, USING A SEMI PREPARATIVE CAPCELL PAK C-18 COLUMN $(1 \times 25$ CM, SHISEIDO CORP.), AND THEIR COMPONENTS WERE ELUTED WITH A LINEAR GRADIENT FROM 10 TO 60\% OF ACETONITRILE CONTAINING 0.1\% TFA, AS DESCRIBED IN THE 'EXPERIMENTAL SECTION'. 
FIGURE 30 - PHYLOGENETIC ANALYSIS AND SEQUENCE ALIGNMENT. (A) AMINO ACID SEQUENCE OF BCSTX1 AND BCSTX2 AND MULTIPLE SEQUENCE ALIGNMENT WITH THE OTHER MEMBERS OF TYPE 1 SEA ANEMONE TOXINS. ALIGNMENT WAS BASED ON THE CYSTEINE RESIDUES. DISULFIDE BRIDGE PATTERN ARE INDICATED. AMINO ACID IDENTITIES (BLACK BOXES) AND SIMILARITY (GREY BOXES) ARE SHOWN. (B) THE PHYLOGENETIC TREE OF TYPE 1 SEA ANEMONE $\mathrm{K}_{\mathrm{V}}$-TOXINS WAS CONSTRUCTED WITH THE NEIGHBOR-JOINING ALGORITHM OF MEGA 4.0. THE CONSENSUS TREE SHOWN SUPPORTS THE SUGGESTED DIVISION OF SEA ANEMONE TYPE 1 INTO TWO DIFFERENT SUBTYPES. THE SCALE BAR SHOWS AMINO ACID SUBSTITUTION RATES. ONLY THE MATURE REGION OF THE SEQUENCES REPORTED AS FC850067, FK724096, FK755121 AND FK747792 WERE USED IN THE ANALYSIS.

FIGURE 31 - ALIGNMENT. AMINO ACID SEQUENCES OF BCSTX1 AND BCSTX2 WERE ALIGNED WITH PART OF THE MATURE PORTION OF THE PUTATIVE PROTEINS FROM ASCARIS SUUM (NEMATODA, SECERNENTEA) (GENBANK \# BM281246), NECATOR AMERICANUS (NEMATODA, RHABDITEA) (GENBANK \# BG734468 AND GE626467), AND NIPPOSTRONGYLUS BRASILIENSIS (NEMATODA, SECERNENTEA) (GENBANK \# BQ529521) AFTER CONDUCTING A BLAST HOMOLOGY SEARCH OF THE EXPRESSED SEQUENCE TAGS (ESTS) ON DATABASES.

FIGURE 32 - ELECTROPHYSIOLOGICAL SCREENING OF BCSTX1 (0.5 $\mu \mathrm{M})$ ON SEVERAL CLONED VOLTAGE-GATED POTASSIUM CHANNEL ISOFORMS BELONGING TO DIFFERENT SUBFAMILIES. REPRESENTATIVE TRACES UNDER CONTROL AND AFTER APPLICATION OF $0.5 \mu \mathrm{M}$ OF BCSTX1 ARE SHOWN. THE ASTERISK INDICATES STEADY-STATE CURRENT TRACES AFTER TOXIN APPLICATION. THE DOTTED LINE INDICATES THE ZERO-CURRENT LEVEL. THIS SCREENING SHOWS THAT BCSTX1 SELECTIVELY BLOCKS KV 1 .X CHANNELS AT A CONCENTRATION OF $0.5 \mu \mathrm{M}$.

FIGURE 33 - INHIBITORY EFFECTS OF BCSTX2 (3 $\mu \mathrm{M})$ ON 12 VOLTAGE-GATED POTASSIUM CHANNELS ISOFORMS EXPRESSED IN $X$. LAEVIS OOCYTES. REPRESENTATIVE WHOLE-CELL CURRENT TRACES IN THE ABSENCE AND IN THE PRESENCE OF $3 \mu \mathrm{M}$ BCSTX2 ARE SHOWN FOR EACH CHANNEL. THE DOTTED LINE INDICATES THE ZERO-CURRENT LEVEL. THE * INDICATES STEADY STATE CURRENT TRACES AFTER APPLICATION OF $3 \mu \mathrm{M}$ BCSTX2. THIS SCREENING CARRIED OUT ON A LARGE NUMBER OF $K_{V}$ CHANNEL ISOFORMS BELONGING TO DIFFERENT SUBFAMILIES SHOWS THAT BCSTX2 SELECTIVELY BLOCKS SHAKER CHANNELS SUBFAMILY. 
FIGURA 34 - FUNCTIONAL FEATURES OF BCSTX1 AND BCSTX2 ON KV CHANNELS. (A B) DOSE-RESPONSE CURVES OF BCSTX1 AND BCSTX2 ON RK $K_{v} 1.1, R K_{v} 1.2, H K_{v} 1.3$, $\mathrm{RK}_{V} 1.6$ AND SHAKER IR CHANNELS. THE CURVES WERE OBTAINED BY PLOTTING THE PERCENTAGE BLOCKED CURRENT AS A FUNCTION OF INCREASING TOXIN CONCENTRATIONS. ALL DATA ARE PRESENTED AS MEAN \pm STANDARD ERROR OF AT LEAST 3 EXPERIMENTS ( $N \geq 3$ ). ( $C-D$ ) CURRENT-VOLTAGE RELATIONSHIP FOR SHAKER IR ISOFORM IN CONTROL CONDITION AND IN THE PRESENCE OF BCSTX1 (500 NM) AND BCSTX2 (50 NM). CURRENT TRACES WERE EVOKED BY 10 MV DEPOLARIZATION STEPS FROM A HOLDING POTENTIAL OF -90 MV. OPEN CIRCLES INDICATES THE $V_{1 / 2}$ IN CONTROL; CLOSED CIRCLES, INDICATES THE ADDITION OF TOXINS. (E - F) PERCENTAGE OF CURRENTS LEFT AFTER APPLICATION OF BCSTX1 (500 NM) AND BCSTX2 (50 NM) ON SHAKER IR CHANNEL. IN A RANGE OF TEST POTENTIALS FROM -10 MV TO +50 MV, NO DIFFERENCE WAS OBSERVED IN THE DEGREE OF BCSTX1- AND BCSTX2-INDUCED BLOCKAGE. ( $G$ - H) REPRESENTATIVE EXPERIMENT OF THE TIME COURSE OF SHAKER IR CURRENT INHIBITION WITH BCSTX1 (500 NM) AND BCSTX2 (3000 NM) AND THE REVERSIBILITY HEREOF. CONTROL (OPEN SQUARE), WASHOUT (OPEN CIRCLES). BLOCKAGE OCCURRED RAPIDLY AND BINDING WAS REVERSIBLE UPON WASHOUT. PLOTS SHOWN ARE A REPRESENTATIVE OF AT LEAST 3 INDIVIDUAL EXPERIMENTS.

FIGURE 35 - 3-D MODEL REPRESENTATION OF BCSTX1 AND BCSTX2. MODELS WERE CONSTRUCTED USING BGK TOXIN AS TEMPLATE (PDB CODE 1BGK). (A) RIBBON REPRESENTATION OF NMR STRUCTURE OF BGK. AMINO ACID SEQUENCE AND SECONDARY STRUCTURE: A-HELIX (RED) AND LOOPS (GRAY). (B) STEREOSCOPIC 3-D MODEL OF BCSTX1. (C) BCSTX2 MOLECULAR MODEL. 


\section{Lista de Tabelas}

TABELA 1 - RELAÇÃO DOS MUTANTES DA TOXINA ABETX1

TABELA 2 - SEQUÊNCIA DE AMINOÁCIDOS DOS PEPTÍDEOS ABETX1 E BCSTX4

TABELA 3 - VALORES DE INIBIÇÃO DA CORRENTE DOS SUBTIPOS DE $K_{v} 1.1, K_{v} 1.2$ E $K_{V} 1.6$ QUANDO APLICADOS ABETX1 NATURAL E OS SEIS MUTANTES A UMA CONCENTRAÇÃO DE $3 \mu \mathrm{M}$.

TABELA 4 - VALORES DE IC I0 $_{5}$ DA TOXINA ABETX1 E DOS SEIS MUTANTES NOS SUBTIPOS DE Kv1.1 E K $K_{v} 1.6$. PORCENTAGEM DE BLOQUEIO DE CORRENTE DO SUBTIPO DE KV1.2 QUANDO APLICADOS $30 \mu \mathrm{M}$ DOS MUTANTES DA ABETX1.

TABELA 5 - DESCRIÇÃO DAS 22 KAPPA-TOXINAS UTILIZADAS NO DENDOGRAMA FUNCIONAL. № DE ACESSO NO UNIPROT, NOMENCLATURA DAS TOXINAS, ESPÉCIE E ANIMAL DE ONDE FORAM EXTRAÍDAS E SEQUÊNCIAS DE AMINOÁCIDOS.

TABELA 6 - POTÊNCIA E SELETIVIDADE DAS "KAPPA-TOXINAS" QUE ATUAM EM KV. AS TOXINAS K-HEFUTOXIN1 (DO ESCORPIÃO HETEROMETRUS FULVIPES), OMTX1-3 (OPISTHACANTHUS MADAGASCARIENSIS), OCYC8 (OPISTHACANTHUS CAYAPORUM) E HELATX1 (HETEROMETRUS LAOTICUS) SÃO AS ÚNICAS "KAPPATOXINAS" QUE JÁ TIVERAM SUA SELETIVIDADE E/OU POTÊNCIA VERIFICADAS PARA DIFERENTES SUBTIPOS DE $\mathrm{K}_{V}$. OS VALORES DE IC ${ }_{50}$ FORAM OBTIDOS ATRAVÉS DE ENSAIOS ELETROFISIOLÓGICOS, UTILIZANDO-SE OVÓCITOS DE XENOPUS LAEVIS E/OU CÉLULAS DE OVÁRIOS DE HAMSTER CHINÊS. 


\section{Lista de símbolos e Abreviaturas}




\section{Lista de abreviaturas}

\begin{tabular}{ll} 
ASIC & canal sensível à acidez ('acid-sensing ion channel') \\
ACN & acetonitrila \\
BCA & 4,4'-dicarboxi-2,2'-biquinolina ácido bicinconínico \\
BDS & Blood Depressing Substances \\
BPTI & inibidores da tripsina pancreática bovina \\
cDNA & ácido desoxirribonucleico complementar \\
cRNA & ácido ribonucleico complementar \\
DDT & dichlorodiphenyltrichloroethano \\
EGFs & fatores de crescimento de epiderme de mamíferos \\
$E_{K}$ & Potencial reverso para íons potássio \\
$h$ & Homo sapiens (humano) \\
HK-ND96 & solução ND96 com alta concentração de íons K ${ }^{+}$ \\
HPLC & High Performance liquid Chromatography \\
IK $_{\text {I }}$ & Corrente de íons K ${ }^{+}$ \\
I25 & isótopo radioativos de lodo \\
IC & concentração inibitória para produzir 50\% do efeito máximo \\
ICK & Inhibitory Cystine Knot \\
KDa & quilo Dalton \\
KV & canal voltagem-dependente de potássio \\
K.U.Leuven & Katholieke Universiteit Leuven \\
mRNA & ácido ribonucleico mensageiro \\
m/z & relação massa/carga \\
Nav & canal voltagem-dependente de sódio \\
ND96 & solução fisiológica para ovócitos de Xenopus laevis \\
PDB & Protein Data Bank \\
PI & Ponto Isoelétrico \\
q.s.p. & quantidade suficiente para \\
$r$ & Rattus norvegicus (rato) \\
RMN & Ressonância Magnética Nuclear \\
RP-HPLC & cromatografia de fase reversa \\
S1 a S6 & segmentos transmembrana 1 a 6 \\
TEA & tetraetilamônio \\
\hline
\end{tabular}


TFA ácido trifluoroacético

UFMG Universidade Federal de Minas Gerais

4-AP 4-Aminopiridina

\section{Lista de símbolos}

$\begin{array}{ll}\AA & \text { Angstrom } \\ { }^{\circ} \mathrm{C} & \text { Grau(s) Celsius } \\ \mathrm{Ca}^{2+} & \text { ion cálcio } \\ \mathrm{CaCl}_{2} \cdot 2 \mathrm{H}_{2} \mathrm{O} & \text { cloreto de cálcio dihidratado } \\ \mathrm{Cl}^{-} & \text {ín cloro } \\ \mathrm{Cs}^{+} & \text {íon Césio } \\ \mathrm{cm} & \text { Centímetro(s) } \\ \mathrm{gr} . & \text { Gramas } \\ \mathrm{G} \Omega & \text { Gigaohms } \\ \mathrm{h} & \text { Hora(s) } \\ \mathrm{H} 2 \mathrm{O} & \text { água } \\ \mathrm{I} & \text { Corrente } \\ \mathrm{K}^{+} & \text {íon Potássio } \\ \mathrm{KCl} & \text { cloreto de potássio } \\ \mathrm{kDa} & \text { QuiloDalton } \\ \mathrm{kHz} & \text { Quilohertz } \\ \mathrm{kvolts} & \text { Quilovolts } \\ \mathrm{L} & \text { Litro(s) } \\ \mathrm{Li} & \text { íon Lítio } \\ \mathrm{M} & \text { Molar } \\ \mathrm{mA} & \text { Miliamperer(s) } \\ \mathrm{MgCl} \cdot 6 \mathrm{H}_{2} \mathrm{O} & \text { cloreto de magnésio hexahidratado } \\ \mathrm{M} \Omega & \text { Megaohm(s) } \\ \mathrm{mg} & \text { Miligrama(s) } \\ \mathrm{mL} & \text { Mililitro(s) } \\ \mathrm{min} & \text { Minuto(s) } \\ \mathrm{ms} & \text { Milisegundo(s) } \\ \mathrm{mM} & \text { Milimolar } \\ & \end{array}$




$\begin{array}{ll}\mathrm{mV} & \text { Milivolt(s) } \\ \mathrm{Na}^{+} & \text {íon Sódio } \\ \mathrm{NaBr} & \text { brometo de sódio } \\ \mathrm{NaCl} & \text { cloreto de sódio } \\ \mathrm{NaHCO}_{3} & \text { bicarbonato de sódio } \\ \mathrm{Na}_{2} \mathrm{SO}_{4} & \text { sulfato de sódio } \\ \mathrm{nM} & \text { Nanomolar } \\ \mathrm{nm} & \text { Nanômetro(s) } \\ \mathrm{nA} & \text { Nanoampere(s) } \\ \mathrm{pH} & \text { Potencial hidrogeniônico } \\ \mathrm{pl} & \text { Ponto isolétrico } \\ \mathrm{pmol} & \text { Picomol } \\ \mathrm{Rb} & \text { íon Rubídio } \\ \mathrm{RPM} & \text { Rotações por minuto } \\ \mathrm{seg} & \text { Segundo(s) } \\ \mathrm{UV} & \text { Ultravioleta } \\ \mathrm{V} & \text { Voltagem } \\ \mathrm{W} & \text { Watt(s) } \\ \mu \mathrm{L} & \text { Microlitro(s) } \\ \mu \mathrm{g} & \text { Micrograma(s) } \\ \mu \mathrm{M} & \text { Micromolar } \\ & \end{array}$

\section{Lista de abreviatura dos aminoácidos}

$\begin{array}{lll}\text { A } & \text { Ala } & \text { Alanina } \\ \text { C } & \text { Cys } & \text { Cisteína } \\ \text { D } & \text { Asp } & \text { Ácido Aspártico } \\ \text { E } & \text { Glu } & \text { Ácido Glutâmico } \\ \text { F } & \text { Phe } & \text { Fenilalanina } \\ \text { G } & \text { Gly } & \text { Glycina } \\ \text { H } & \text { His } & \text { Histidina } \\ \text { I } & \text { lle } & \text { Isoleucina } \\ \text { K } & \text { Lys } & \text { Lisina } \\ \text { L } & \text { Leu } & \text { Leucina }\end{array}$




$\begin{array}{lll}\text { M } & \text { Met } & \text { Metionina } \\ \text { N } & \text { Asn } & \text { Asparagina } \\ \text { P } & \text { Pro } & \text { Prolina } \\ \text { Q } & \text { Gln } & \text { Glutamina } \\ \text { R } & \text { Arg } & \text { Arginina } \\ \text { S } & \text { Ser } & \text { Serina } \\ \text { T } & \text { Thr } & \text { Treonina } \\ \text { V } & \text { Val } & \text { Valina } \\ \text { W } & \text { Trp } & \text { Triptofano } \\ \text { Y } & \text { Tyr } & \text { Tirosina }\end{array}$


Introdução 1

1. Introdução 


\section{Canais iônicos}

A membrana celular de eucariotos consiste de um mosaico de lipídios, carboidratos e proteínas. As proteínas são o segundo maior constituinte, sendo classificadas como periféricas e integrais. As proteínas integrais, também conhecidas como transmembrana, possuem uma região hidrofóbica e outra hidrofílica. Cada região possui uma composição de aminoácidos e uma estrutura secundária característica, permitindo sua interação, através de ligações não covalentes, com a membrana plasmática, tanto em sua porção hidrofílica, quanto hidrofóbica (belémHill et al, 2012a).

Cinco tipos funcionais de proteínas transmembrana são encontrados: canais, transportadoras (carreadoras), enzimas, receptores e proteínas estruturais. Os canais iônicos permitem a passagem de íons, presentes em soluções aquosas, pelo processo de difusão, seguindo seu gradiente elétrico e químico através da membrana. Este mecanismo de transporte se faz necessário, uma vez que a membrana plasmática possui um caráter hidrofóbico em seu interior, impossibilitando que solutos hidrofílicos a atravessem (Hill et al, 2012a).

Do ponto de vista estrutural, estes canais iônicos são constituídos de uma ou mais proteínas que atravessam a membrana, formando uma região central, denominada de poro. Este permite a passagem seletiva de diferentes íons, como consequência de uma alteração de sua conformacão causada por um estímulo, que aumenta ou diminui a sua permeabilidade. De acordo com o mecanismo de ativação do canal, estes são classificados em: (1) canais que se abrem em resposta ao estiramento, (2) canais controlados por proteínas cinases, (3) canais com mecanismo de abertura e fechamento controlado por um ligante e (4) canais voltagem - dependentes (Hill et al, 2012b). 


\subsection{Canais iônicos dependentes de voltagem}

\subsubsection{Descoberta dos canais voltagem - dependentes}

Em meados dos anos 1950, em uma série de artigos, Hodgkin e Huxley definiram as três principais características biofísicas envolvidas com a geração e a propagação do potencial de ação: ativação dependente de voltagem, seletividade iônica e a permeabilidade mediada pelo movimento. No entanto, na época, não se sabia da existência dos canais iônicos e, portanto, os autores caracterizaram a permeabilidade como sendo uma consequência do movimento de alguns componentes da membrana, que se comportam como se tivessem uma grande carga, ou um momento dipolo orientado pela diferença de voltagem da membrana (Armstrong \& Hille, 1998; Hodgkin \& Huxley, 1952a; Hodgkin \& Huxley, 1952b; Hodgkin \& Huxley, 1952c; Hodgkin et al, 1949).

As primeiras evidências de como seria a estrutura destes componentes de membrana (canais iônicos) surgiram em 1959, quando Mullins propôs que a membrana celular possuía poros que somente permitiam a passagem de íons após sua desidratação, sendo a seletividade iônica uma consequência da diferença em seus raios atômicos (Mullins, 1959). Posteriormente, novas evidências apoiaram esta hipótese e demonstrou-se que a força eletrostática do Filtro de Seletividade do canal e a termodinâmica do sistema também eram importantes para a seletividade (Bezanilla, 2008; Bezanilla \& Armstrong, 1972; Eisenman \& Dani, 1987; Noskov et al, 2004)

Em 1964, Narahashi e colaboradores caracterizaram a tetrodotoxina (TTX) como uma toxina que bloqueia especificamente a corrente dos íons $\mathrm{Na}^{+}$ (Narahashi et al, 1964). Posteriormente, com a descoberta que o cátion tetraetilamônio (TEA) era capaz de bloquear somente a corrente dos íons $\mathrm{K}^{+}$, confirmou-se a proposição inicial de que a condutividade dos íons $\mathrm{Na}^{+}$e $\mathrm{K}^{+}$ ocorre por meio de diferentes componentes (canais iônicos) presentes na membrana (Armstrong \& Binstock, 1965; Tasaki \& Hagiwar, 1957). 
Durante a década de 1970, experimentos eletrofisiológicos utilizando-se o TEA permitiram provar que os canais voltagem - dependentes de $\mathrm{K}^{+}$sofriam alterações em suas conformações mediadas pela diferença de voltagem. Uma vez que ao se substituir um dos grupos etil do TEA, o bloqueio da corrente somente ocorreu após a despolarização da membrana. Também se descreveu a competição direta entre o TEA e os íons $\mathrm{K}^{+}$, o que sugeria uma única região do canal que ao mesmo tempo era responsável pela seletividade e, pela passagem dos íons (posteriormente caracterizada como o Filtro de Seletividade do poro do canal) (Armstrong, 1971; Bezanilla, 2008; Bezanilla \& Armstrong, 1972; Hille, 1975).

Apesar das evidências conduzirem a uma provável estrutura dos canais iônicos, a confirmação somente ocorreu em consequência do avanço das técnicas de biologia molecular, na década de 1980. A clonagem molecular permitiu caracterizar a sequência de aminoácidos dos canais iônicos, sendo que o primeiro a ser clonado foi o canal voltagem - dependente de $\mathrm{Na}^{+}$(Noda et al, 1984), seguido pela clonagem do canal voltagem - dependente de $\mathrm{Ca}^{2+}$ (Tanabe et al, 1987) e, posteriormente determinou-se a estrutura primária do canal voltagem - dependente de $\mathrm{K}^{+}$(Kamb et al, 1987; Papazian et al, 1987; Pongs et al, 1988).

A descoberta da sequência de aminoácidos permitiu a caracterização estrutural dos canais em seis segmentos transmembranares, sendo que os canais voltagem - dependentes de $\mathrm{Na}^{+}$e $\mathrm{Ca}^{2+}$ apresentavam quatro repetições (domínios) destes seis segmentos transmembranares (Noda et al, 1984; Tanabe et al, 1987). Por sua vez, o canal voltagem - dependente de $\mathrm{K}^{+}$é formado por quatro subunidades e, para que seu modelo estrutural fosse determinado, utilizou-se de técnicas biofísicas e eletrofisiológicas, com o auxílio de toxinas escorpiônicas que serviram como ferramentas experimentais (Christie et al, 1990; MacKinnon, 1991a; MacKinnon \& Miller, 1989).

Com o aumento do número de sequências determinadas, começou-se a estudar a função de grupos de aminoácidos que eram conservados ao longo das diferentes sequências primárias. Para tal, experimentos envolvendo mutações sítio-dirigidas dos aminoácidos do segmento transmembrana S4 
foram realizados, comprovando-se sua importância na abertura do canal em resposta à diferença de voltagem da membrana (Papazian et al, 1991; Stuhmer et al, 1989). Também foram realizados experimentos de mutação sítio-dirigida com o Filtro de Seletividade, para verificar sua importância na seletividade iônica (Garcia et al, 2001; Heginbotham et al, 1992; Heginbotham et al, 1994; Heginbotham \& MacKinnon, 1992).

Outro aspecto relevante foi a utilização de toxinas peptídicas isoladas de escorpiões, aranhas, anêmonas do mar, serpentes, entre outros animais, que serviram de modelos para o estudo da estrutura e função dos canais voltagem - dependentes, permitindo a compreensão da funcionalidade das diferentes regiões do canal, suas subunidades e unidade auxiliares (Banks et al, 1979; Blatz \& Magleby, 1986; Dolly et al, 1984; Jenkinson, 2006; Miller et al, 1985).

O acúmulo de evidências tornava o modelo proposto para os canais voltagem - dependente cada vez mais sólido, até que em 1998 determinou-se a primeira estrutura tridimensional de um canal de voltagem - dependente de $\mathrm{K}^{+}$(KcsA) com apenas dois segmentos transmembrana, isolado da bactéria Streptomyces lividans (Doyle et al, 1998). Posteriormente, outros canais iônicos tiveram suas estruturas determinadas: em 2002, Jiang e colaboradores determinaram a estrutura de um canal de $\mathrm{K}^{+}$ativado por $\mathrm{Ca}^{2+}$ (MthK) (Jiang et al, 2002a). Em 2003, determinou-se a estrutura de um canal (KvAP) da bactéria Aeropyrum pernix (Jiang et al, 2003a) e em 2005 foi determinada a estrutura do subtipo de $\mathrm{K}_{\mathrm{v}} 1.2$ de mamífero (Long et al, 2005a). Em 2007, determinou-se a estrutura de um canal quimérico, formado pelas subunidades de $\mathrm{K}_{\mathrm{v}} 1.2$ e Kv2.1 (Long et al, 2007) e recentemente, a primeira estrutura do canal voltagem dependente de $\mathrm{Na}^{+}$foi elucidada (Payandeh et al, 2011).

Contudo, pode-se afirmar que concomitantemente aos avanços das técnicas de experimentação biológica, novas descobertas foram sendo realizadas e, atualmente, dada a grande diversidade de canais já descritos e caracterizados, estes são classificados como membros de uma superfamília de proteínas, a qual inclui os canais voltagem - dependente de $\mathrm{Na}^{+}, \mathrm{Ca}^{2+}, \mathrm{K}^{+}$, canais ativados por nucleotídeos cíclicos e canais TRP (sigla de 'Transient Receptor Potential) (Figura 1) (Yu \& Catterall, 2004). 


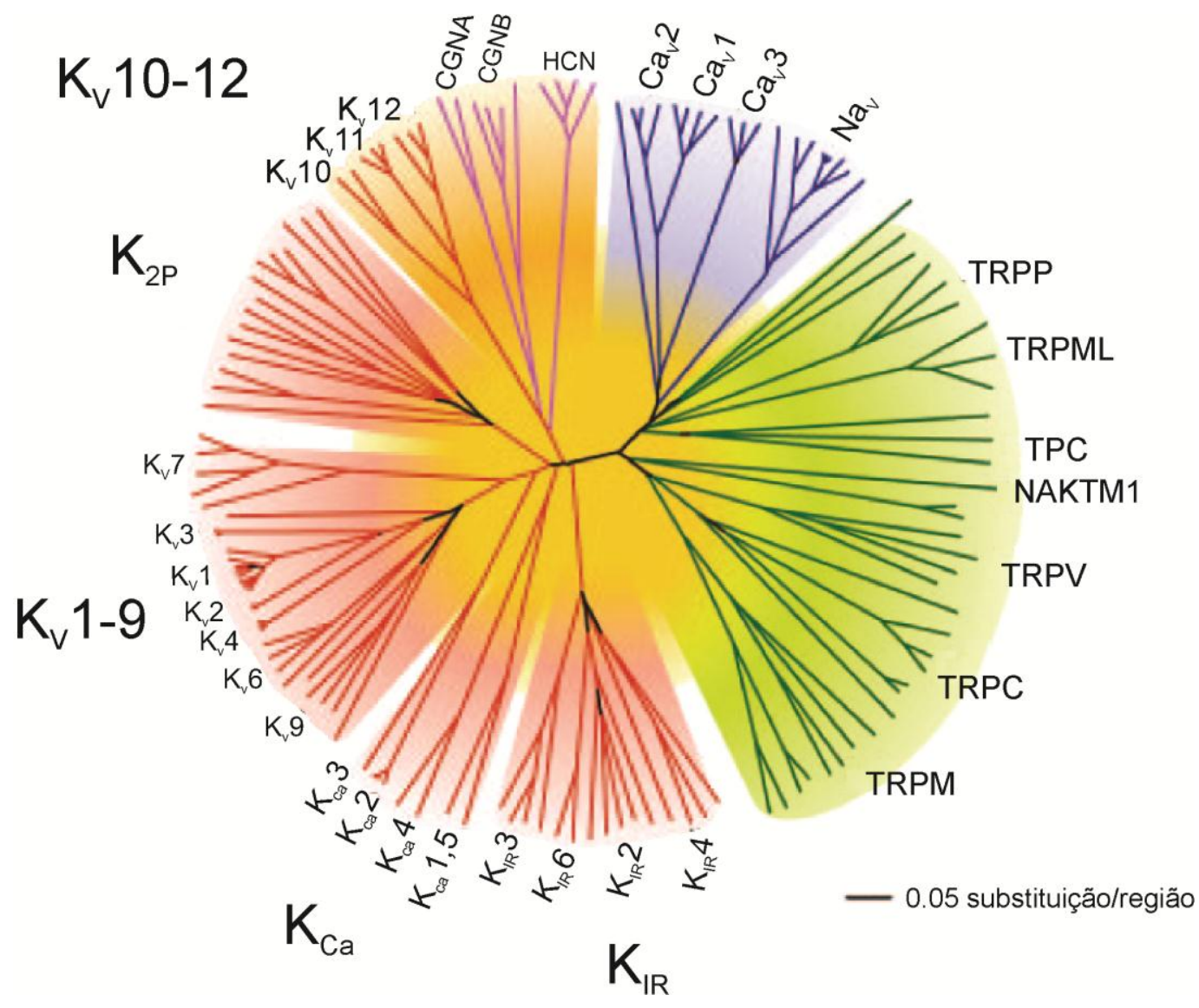

Figura 1 - Superfamília de canais iônicos. O dendograma representa 143 membros das diferentes famílias de canais iônicos. Os ramos em azul são representados pelos canais voltagem - dependentes de $\mathrm{Na}^{+}$e $\mathrm{Ca}^{2+}$. Os ramos vermelhos indicam os canais seletivos para os íons $\mathrm{K}^{+}$. Em magenta estão os canais ativados por nucleotídeos cíclicos e em verde tem-se os diferentes "Transient Receptor Potential". Figura modificada de Catterall e colaboradores (Catterall et al, 2005).

\subsubsection{Estrutura dos canais voltagem - dependentes}

Canais voltagem - dependentes de $\mathrm{Na}^{+}, \mathrm{Ca}^{2+}$ e $\mathrm{K}^{+}$são membros de uma superfamília de proteínas integrais com uma arquitetura estrutural semelhante. Os canais voltagem - dependentes de $\mathrm{Na}^{+}$e $\mathrm{Ca}^{2+}$ são compostos de uma única cadeia polipeptídica, denominada de a subunidade, responsável pela formação do poro do canal, a qual pode estar associada a diferentes subunidades auxiliares (Catterall, 1988). A a subunidade é composta por quatro 
domínios homólogos (I - IV), sendo que cada domínio é formado por um núcleo estrutural ('core motif) com seis segmentos transmembranares em a hélice (segmentos S1 a S6) (Kayano et al, 1988; Noda et al, 1984; Tanabe et al, 1987).

Por sua vez, os canais voltagem - dependentes de $\mathrm{K}^{+}$são tetrâmeros, ou seja, são formados por quatro proteínas (subunidades), cada qual contendo seis segmentos transmembranares em a hélice (S1-S6), que se ligam covalentemente para formar o canal. Esses canais podem também estar associados a diferentes subunidades auxiliares ( $\left.K_{v} \beta 1-K_{v} \beta 3\right)$ (Baumann et al, 1987; Kamb et al, 1987; Papazian et al, 1987).

As subunidades auxiliares possuem sequências primárias que não se assemelham à da subunidade principal ( $\alpha$ subunidade), e são capazes de alterar as propriedades eletrofisiológicas e/ou biofísicas e os níveis e padrões de expressão dos canais voltagem - dependentes de $\mathrm{Na}^{+}, \mathrm{Ca}^{2+}$ e $\mathrm{K}^{+}$. Além disso, estes canais também podem interagir com proteínas adicionais, tais como enzimas reguladoras e os elementos do citoesqueleto (Isom et al, 1994).

Os segmentos S1 a S4 dos canais voltagem - dependentes formam o "domínio sensor de voltagem", responsável por alterações de conformação estrutural que ocorrem em resposta às diferenças de voltagem da membrana (Catterall et al, 2005). O segmento S4 é considerado o principal segmento transmembrana do sensor de voltagem, sendo responsável pelo deslocamento de cargas positivas ("gating charges") ao longo do campo elétrico transmembranar (Bezanilla, 2000).

Este segmento é composto por aminoácidos positivos (geralmente Arginina) e aminoácidos hidrofóbicos. A disposição repetitiva destes aminoácidos na cadeia peptídica (um aminoácido positivo, seguido de dois aminoácidos hidrofóbicos) confere uma estrutura secundária em a hélice, na qual as cadeias laterais dos aminoácidos positivos formam interações eletrostáticas com os aminoácidos negativos dos segmentos transmembranares S1, S2 e S3 (Catterall, 1988; Papazian et al, 1995; TiwariWoodruff et al, 1997). 
Os segmentos S5 e S6 formam o "domínio do poro" do canal. Na alça de ligação entre os segmentos S5 e S6, tem-se a região do poro, também conhecida como "P-region". Quando quatro "P-regions", de cada uma das subunidades ou domínios dos canais voltagem - dependentes estão tridimensionalmente próximas, forma-se o poro por onde ocorre a passagem dos íons (Yellen, 1998). No entanto, a passagem dos íons é seletiva, uma vez que nesta região se encontram os aminoácidos do Filtro de Seletividade, além de outros que estão presentes nos segmentos S5 e S6, que também são importantes para a seletividade iônica (Figura 2) (Lopez et al, 1994; Ragsdale et al, 1994; Shieh \& Kirsch, 1994).

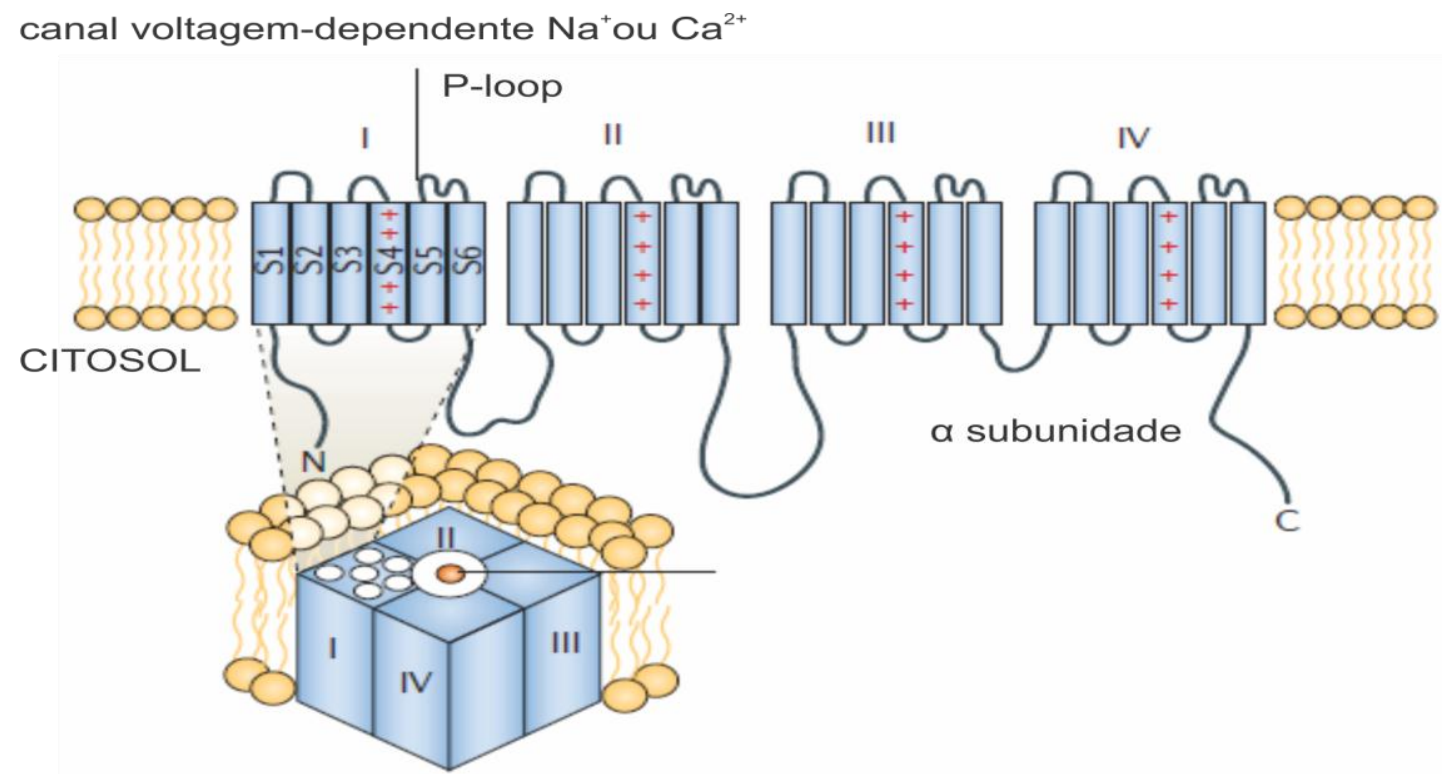

canal voltagem-dependente $\mathrm{K}^{+}$

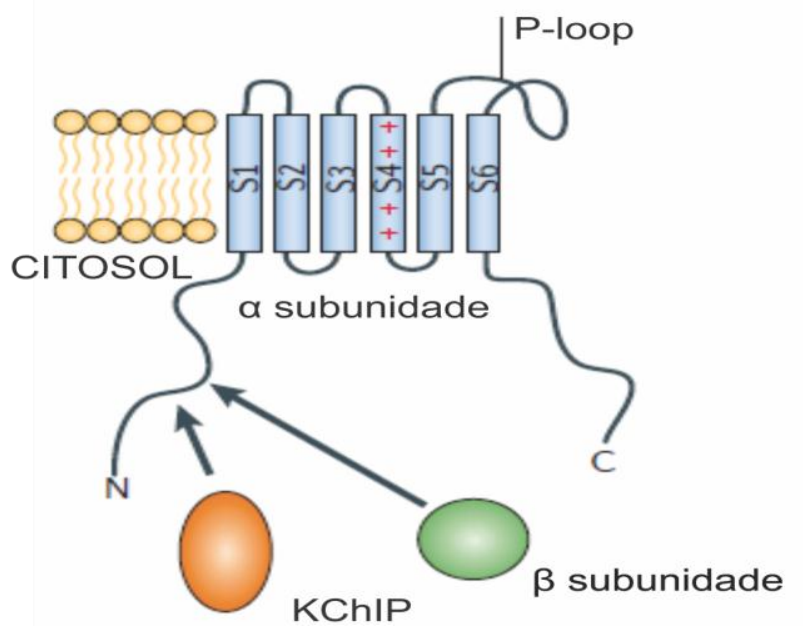


Figura 2 - Estrutura dos canais voltagem - dependentes de $\mathrm{Na}^{+}, \mathrm{Ca}^{2+}$ e $\mathrm{K}^{+}$. Os canais voltagem - dependentes de $\mathrm{Na}^{+}$e $\mathrm{Ca}^{2+}$ são formados por uma única cadeia polipeptídica com quatro domínios (I - IV), cada qual contendo seis segmentos transmembrana. $\mathrm{O}$ canal voltagem - dependente de $\mathrm{K}^{+}\left(\mathrm{K}_{\mathrm{V}}\right)$ é formado por quatro subunidades, cada qual contendo seis segmentos transmembrana. Assim como os canais voltagem - dependentes de $\mathrm{Na}^{+} \mathrm{e}$ $\mathrm{Ca}^{2+}$, o $\mathrm{K}_{\mathrm{v}}$ pode estar associado a subunidades auxiliares ( $\beta$ subunidade ou KChIP). Figura modificada de (Lai \& Jan, 2006).

\subsubsection{Teoria evolutiva dos canais voltagem - dependentes}

Dada à alta identidade da estrutura primária, principalmente na região do segmento S4 do domínio sensor de voltagem e, a grande similaridade estrutural entre os canais voltagem - dependentes de $\mathrm{Na}^{+}, \mathrm{K}^{+}$e $\mathrm{Ca}^{2+}$, postulouse uma divergência evolutiva a partir de uma arquitetura estrutural ancestral em comum. Acredita-se que primeiramente surgiram os canais de voltagem dependentes de $\mathrm{K}^{+}$, derivados de canais de $\mathrm{K}^{+}$ancestrais. Provavelmente, estes canais ancestrais eram semelhantes aos encontrados atualmente, desde bactérias até mamíferos, com apenas dois segmentos transmembranares em cada uma das quatro subunidades, os quais correspondem ao "domínio do poro" (segmentos S5 e S6) dos canais voltagem - dependentes com seis segmentos.

Acredita-se que este canal ancestral com apenas dois segmentos (que não era voltagem - dependente) se associou a outra proteína, a qual provavelmente era formada pelos segmentos $S 1$ a $S 4$, responsáveis pelo "domínio sensor de voltagem". A partir daí, surgiram os canais voltagem dependentes de $\mathrm{K}^{+} \mathrm{e}$, a partir destes, surgiram os canais que possuem uma extensão de sua cadeia peptídica na região $\mathrm{N}$-terminal, responsável pelo seu mecanismo de inativação, os canais de $\mathrm{K}^{+}$ativados por $\mathrm{Ca}^{2+}$ e os canais de $\mathrm{K}^{+}$ ativados por nucleotídeos cíclicos presentes no citosol. 
Acredita-se, também, que os canais voltagem - dependentes de $\mathrm{Na}^{+} \mathrm{e} \mathrm{Ca}^{2+}$ evoluíram a partir dos canais de $\mathrm{K}^{+}$voltagem - dependentes, como consequência da duplicação gênica e sucessivas mutações, que resultaram em uma única proteína formada por quatro repetições (domínios I - IV) de seis segmentos transmembranares. Atualmente, os canais voltagem - dependentes da $\mathrm{Na}^{+}, \mathrm{K}^{+}$e $\mathrm{Ca}^{2+}$ são membros da terceira maior superfamília de proteínas sinalizadoras presentes no genoma humano, estando atrás somente de proteínas cinases e receptores acoplados à proteína G (Anderson \& Greenberg, 2001; Catterall et al, 2005; Hill et al, 2012c; Yu \& Catterall, 2003)

\subsubsection{Fisiologia dos canais voltagem - dependentes}

Canais voltagem - dependentes de $\mathrm{Na}^{+}$e $\mathrm{K}^{+}$são responsáveis pela sinalização elétrica celular, estando envolvidos com a liberação de $\mathrm{Ca}^{2+}$ intracelular, sinapses elétricas, secreção hormonal de sinapses químicas, contração da musculatura, percepção do meio ambiente, além de muitas outras funções em células não excitáveis, tais como expressão gênica e divisão celular. Em suma, são os principais responsáveis pela geração e propagação do potencial de ação e, consequentemente, da integração do funcionamento do sistema nervoso (Ackerman \& Clapham, 1997).

A geração do potencial de ação é o resultado da diferença de permeabilidade da membrana celular aos íons $\mathrm{Na}^{+}$e $\mathrm{K}^{+}$. Este fenômeno tem início quando ocorre uma mudança no potencial de repouso da membrana, capaz de gerar a abertura de canais voltagem - dependentes, permitindo, consequentemente, a passagem destes íons através da membrana plasmática.

Durante 0 potencial de ação, observa-se uma diferença na permeabilidade dos íons $\mathrm{Na}^{+}$e $\mathrm{K}^{+}$e, para se determinar o potencial de membrana $\left(\mathrm{V}_{m}\right)$ deve-se levar em consideração o fato da corrente total que flui através da membrana ser o resultado da soma das correntes iônicas individuais, como determinado pela equação de Goldman-Hodgkin-Katz: 


$$
\mathrm{V}_{m}=\frac{\mathrm{RT}}{z \mathrm{~F}} \ln \frac{P_{\mathrm{K}}\left[\mathrm{K}^{+}\right]_{\mathrm{O}}+P_{\mathrm{Na}}\left[\mathrm{Na}^{+}\right]_{\mathrm{O}}}{P_{\mathrm{K}}\left[\mathrm{K}^{+}\right]_{\mathrm{l}}+P_{\mathrm{Na}}\left[\mathrm{Na}^{+}\right]_{\mathrm{I}}}
$$

Onde, $\mathrm{V}_{m}$ é o potencial de membrana, $\mathrm{R}$ é a constante dos gases, $\mathrm{T}$ é a temperatura, $z$ é a valência da carga do íon, $F$ é a constante de Fraday, In, logaritmo na base $10, P_{\mathrm{K}}$ e $P_{\mathrm{Na}}$, permeabilidades dos íons $\mathrm{K}^{+}$e $\mathrm{Na}^{+},\left[\mathrm{K}^{+}\right]_{\mathrm{O}}$ e $\left[\mathrm{Na}^{+}\right]_{\mathrm{O}}$, são as concentrações dos íons $\mathrm{K}^{+} \mathrm{e} \mathrm{Na}^{+}$no meio extracelular e, $\left[\mathrm{K}^{+}\right]_{1} \mathrm{e}$ $\left[\mathrm{Na}^{+}\right]_{1}$, são as concentrações dos íons $\mathrm{K}^{+}$e $\mathrm{Na}^{+}$no meio intracelular (Hodgkin \& Huxley, 1952c).

Dessa forma, é possível observar diferentes fases do potencial de ação de acordo com a permeabilidade dos íons. Inicialmente, tem-se uma reversão do potencial de membrana, causada pelo aumento da permeabilidade dos íons $\mathrm{Na}^{+}$, em decorrência da abertura de canais voltagem - dependentes de $\mathrm{Na}^{+}$. Posteriormente, estes canais ficam inativados e, concomitantemente, ocorre à abertura tardia, por alguns milissegundos, dos canais voltagem - dependentes de $\mathrm{K}^{+}$. Aumentando a permeabilidade dos íons $\mathrm{K}^{+}$e restaurando o potencial de repouso da membrana (Hill et al, 2012c).

\subsection{Canais voltagem - dependentes de $K^{+}$}

\subsubsection{Classificação e distribuição}

Os canais de $\mathrm{K}^{+}$são responsáveis por aproximadamente $50 \%$ dos genes da superfamília de proteínas sinalizadoras, com mais de 80 membros já descritos. Estes são classificados em quatro tipos, de acordo com o número de segmentos transmembrana e o seu mecanismo de atuação: canais 'inwardly rectifying', com dois segmentos transmembrana (Kir), canais com dois poros e quatro segmentos transmembranares (K2P ou "leak channels"), canais com seis segmentos transmembranares, ativados por $\mathrm{Ca}^{2+}\left(\mathrm{K}_{\mathrm{Ca}}\right)$, canais voltagem - 
dependentes $\left(\mathrm{K}_{\mathrm{V}}\right)$, que também são formados por seis segmentos transmembranares, e os canais com oito segmentos transmembranares e dois poros. Cada um destes tipos pode ser classificado em famílias e subdividido em subfamílias, cada qual contendo vários membros (subtipos) estritamente relacionados (Wulff et al, 2009).

Os primeiros estudos realizados com o genoma da popularmente conhecida mosca de fruta (Drosophila melanogaster) identificaram quatro diferentes subfamílias de canais voltagem - dependentes de $\mathrm{K}^{+}$: Shaker $\left(\mathrm{K}_{\mathrm{V}} 1\right)$, Shab (Kv2), Shaw (Kv3) e, Shal (Kv4) (Butler et al, 1989). Posteriormente, trabalhos realizados com o genoma de mamíferos permitiram a identificação de outras quatro subfamílias: $\mathrm{K}_{\mathrm{v}} 5, \mathrm{~K}_{\mathrm{v}} 6, \mathrm{~K}_{\mathrm{v}} 8$ e $\mathrm{K}_{\mathrm{v}} 9$. Estas oito subfamílias são caracterizadas pela rápida cinética de ativação e são classificadas como pertencentes à família $\mathrm{K}_{\mathrm{V}}$. Outros subtipos de canais voltagem - dependentes também foram posteriormente caracterizados e classificados como pertencentes às famílias EAG, formada pelas subfamílias $K_{v} 10, K_{v} 11$ e $K_{v} 12$, e família KQT, formada pela subfamília Kv7 (subtipos KCNQ1 - KCNQ5) (Figura 3) (Coetzee et al, 1999; Gutman et al, 2003). 


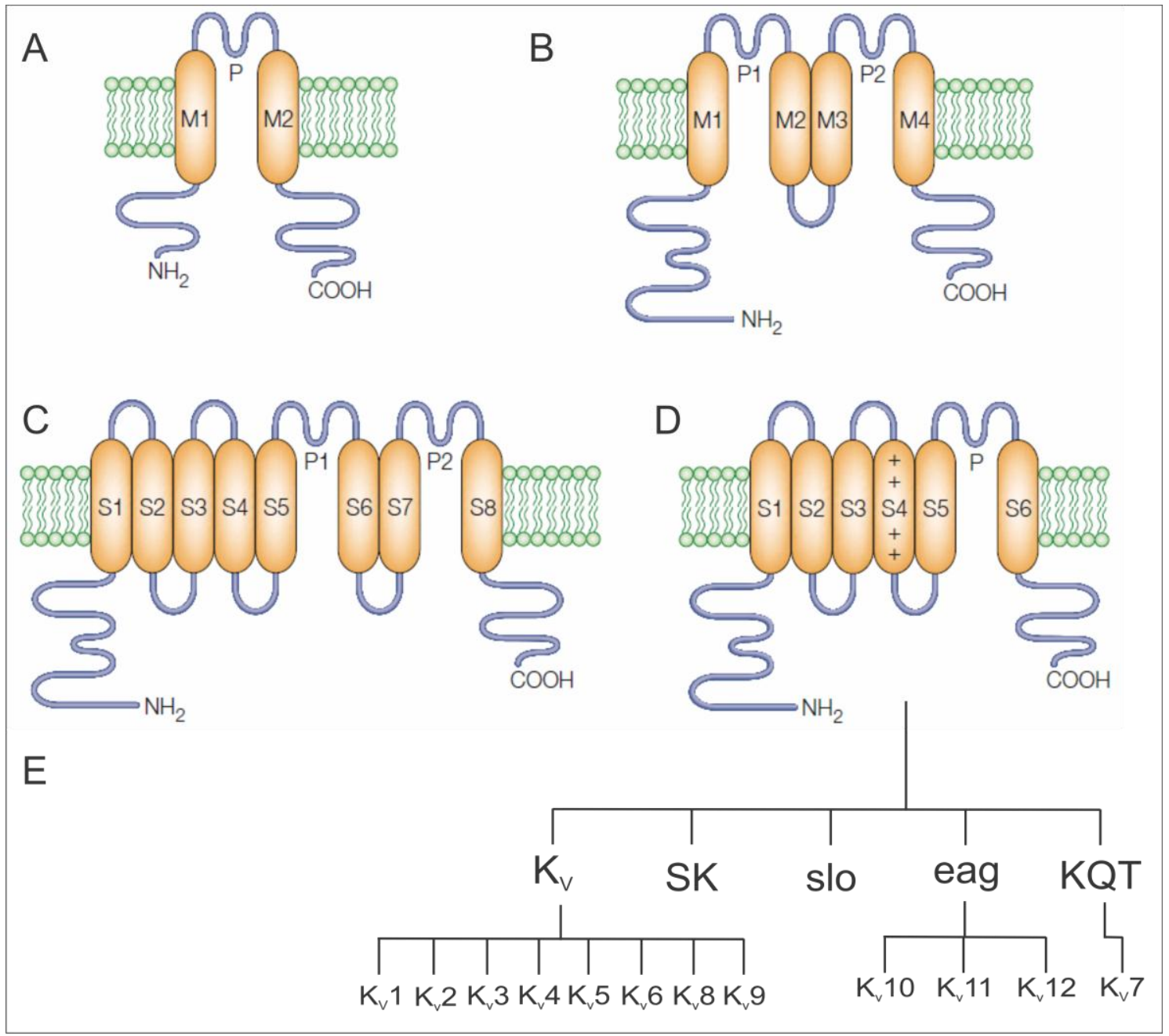

Figura $\mathbf{3}$ - Classificação dos canais seletivos para o íon $\mathrm{K}^{+}$. A - canais 'inwardly rectifying', com dois segmentos transmembrana (Kir). B - canais com dois poros e quatro segmentos transmembranares (K2P ou "leak channels"), C - canais com oito segmentos transmembranares e dois poros. D - canais com seis segmentos transmembranares que podem ser ativados por $\mathrm{Ca}^{2+}\left(\mathrm{K}_{\mathrm{Ca}}\right)$ ou dependentes de voltagem $\left(K_{\mathrm{v}}\right)$. E - Subdivisão dos canais com seis segmentos transmembrana em cinco famílias: $K_{V}$, eag, KQT, SK e slo. As famílias SK e slo são formadas por canais ativados por $\mathrm{Ca}^{2+}$, ao passo que as famílias $\mathrm{K}_{\mathrm{V}}$, eag e KQT são formadas por canais voltagem - dependentes (subfamílias de $\mathrm{K}_{\mathrm{v}} 1$ $\left.K_{v} 12\right)$. Figura modificada de (Choe, 2002; Coetzee et al, 1999)

Devido à grande quantidade de famílias e subfamílias já caracterizadas, apresentaremos a seguir uma descrição mais detalhada a respeito de algumas 
subfamílias pertencentes à família $\mathrm{K}_{\mathrm{v}}$, uma vez que estes canais constituem o foco da nossa investigação.

\section{Subfamília Shaker $\left(K_{V} 1\right)$}

Já se têm descrito oito genes dentro desta subfamília, os quais correspondem aos subtipos de $\mathrm{K}_{\mathrm{V}} 1.1$ a $\mathrm{K}_{\mathrm{V}} 1.8$. No entanto, como estes podem formar complexos heterotetraméricos no sistema nervoso central, a diversidade de subtipos encontrados é muito maior. Estes subtipos também são amplamente expressos em diversos órgãos, tais como, coração e rim, em tecidos periféricos do sistema vascular e em células do sistema imune (Rudy, 2010).

\section{Subfamília Shab (Kv2)}

Os dois subtipos já caracterizados são os Kv2.1 e Kv2.2. Estes são encontrados no córtex cerebral, hipocampo e cerebelo. Acredita-se que estão presentes em todas as células e interneurônios do tecido cerebral e estão localizados principalmente e, em grande quantidade, na região do soma e na região dendrítica próxima ao corpo celular neuronal. Também já foi descrita a presença destes subtipos em células $\beta$ do tecido pancreático (Dai et al, 2009; Hwang et al, 1993; Murakoshi \& Trimmer, 1999).

\section{Subfamília Shaw $\left(K_{v} 3\right)$}

Cada subtipo de Kv3 exibe um padrão peculiar de expressão entre as populações de células do sistema nervoso. Os subtipos $K_{v} 3.1$ - Kv3.3 são expressos no sistema nervoso central e geralmente são encontrados em neurônios (tanto no soma, quanto no axônio) com terminações sinápticas GABAérgicas e, em interneurônios. Por sua vez, o subtipo $K_{v} 3.4$ não é tão usualmente encontrado no cérebro, porém há uma grande expressão destes na musculatura esquelética (Lenz et al, 1994; Perney et al, 1992; Veh et al, 1995). 
Dentre os três subtipos já caracterizados nesta subfamília, somente os $\mathrm{K}_{\mathrm{v}} 4.2$ e $\mathrm{K}_{\mathrm{v}} 4.3$ são altamente expressos no sistema nervoso central e coração. Por sua vez, o $\mathrm{K}_{\mathrm{v}} 4.1$ é encontrado em baixos níveis de expressão no sistema nervoso central (hipocampo e córtex cerebelar) e, fora do sistema nervoso, é encontrado em diferentes órgãos: coração, fígado e rim (Serodio \& Rudy, 1998).

\section{Subfamilia ether-à-go-go (erg ou $\left.K_{v} 11\right)$}

Atualmente três subtipos já foram descritos para esta subfamília ( $\mathrm{K}_{\mathrm{V}} 11.1$ - $K_{v} 11.3$ ). O subtipo $K_{v} 11.1$ (Erg1) foi primeiramente isolado do coração de humanos e, por isso, também é conhecido como $h$ ERG ("human ether-à-gogo"), porém também já foi identificado em interneurônios do sistema nervoso central. Os outros dois subtipos ( $K_{v} 11.2$ e $K_{v} 11.3$ ) não são encontrados no coração, mas já foi comprovada sua presença no hipocampo. Interessantemente, no sistema nervoso central, estes canais também tendem a formar heterotetrâmeros (Vacher et al, 2008).

\subsubsection{Cinética de ativação e inativação e seletividade iônica}

Aproximadamente $30 \%$ da energia proveniente do metabolismo celular são gastos com a manutenção do gradiente eletroquímico dos íons $\mathrm{Na}^{+}$e $\mathrm{K}^{+}$ através da membrana. Esta energia é convertida em movimento do canal, possibilitando sua abertura ou fechamento e, consequentemente, aumentando ou diminuindo a permeabilidade dos íons através da membrana (Ackerman \& Clapham, 1997).

Os canais voltagem - dependentes de $\mathrm{K}^{+}$possuem mais de um mecanismo responsável por sua abertura e fechamento. $O$ movimento de abertura do canal é denominado de ativação e ocorre em resposta à despolarização da membrana. Posteriormente à sua ativação, quando o potencial de membrana volta a valores negativos, o canal se fecha, em um processo denominado de desativação. Em determinadas situações fisiológicas 
em que o potencial de membrana é mantido em valores positivos, o canal também irá se fechar, porém através de um processo conhecido como inativação, mediado tanto pela porção Amino-terminal do canal (denominado de "N-type") quanto pela porção Carboxi-terminal ("C-type").

\section{Sensor de voltagem}

Como já discutido anteriormente, os segmentos $\mathrm{S} 1$ a $\mathrm{S} 4$ dos canais voltagem - dependentes estão envolvidos com as alterações de conformação estrutural que ocorrem em resposta à despolarização da membrana (Jiang et al, 2003a). Com o intuito de se compreender este fenômeno, os primeiros trabalhos realizados, utilizando-se a técnica de "voltage - clamp" definiram que diferentes valores de voltagem de membrana causavam diferentes alterações na conformação do canal, resultando em diferentes valores de corrente, denominada de "gating current" (Armstrong \& Bezanilla, 1973; Schneider \& Chandler, 1973).

Medidas eletrofisiológicas realizadas em canais com mutações sítio dirigidas nos segmentos S2 (substituição de aminoácidos negativos por neutros) e S4 (substituição de aminoácidos positivos por neutros) resultaram em uma redução na "gating current". Tal condição permite afirmar que ambos os segmentos são extremamente importantes, pois estão diretamente envolvidos com a detecção das diferenças de voltagem da membrana e, consequentemente, no "gating" (abertura e fechamento) do canal (Papazian et al, 1995; Seoh et al, 1996; Tiwari-Woodruff et al, 1997). Outros experimentos provaram que os aminoácidos positivos do segmento S4 são capazes de se deslocar ao longo da membrana plasmática e até ficarem expostos ao meio extracelular, quando a membrana sofre diferentes pulsos de voltagem despolarizante (Larsson et al, 1996; Mannuzzu et al, 1996; Yang \& Horn, 1995).

Tais evidências, juntamente com análises estruturais dos canais voltagem - dependentes de $\mathrm{K}^{+}$(Doyle et al, 1998; Jiang et al, 2003b; Long et al, 2005b), permitiram propor diferentes mecanismos de movimento do domínio sensor de voltagem. Primeiramente, Jiang e colaboradores (2003), a partir da determinação da estrutura do canal $\left(\mathrm{K}_{\mathrm{v}} \mathrm{AP}\right)$ da arqueobactéria termofílica 
Aeropyrum pernix, concluíram que o segmento S4 se encontrava na interface entre o citoplasma e a membrana plasmática e era capaz de se deslocar mais de $15 \AA$ ao longo da membrana plasmática, durante sua despolarização. Os autores ainda propuseram que os resíduos positivos do segmento S4 estavam expostos aos lipídios de membrana, permitindo ao sensor de voltagem "sentir e responder" às forças eletrostáticas e hidrofóbicas que estariam envolvidas com o "gating" do canal (Jiang et al, 2003a; Jiang et al, 2003b).

No entanto, possíveis interferências decorrentes dos métodos utilizados, levaram Long e colaboradores (2005) proporem um novo modelo baseando-se na estrutura do $K_{v} 1.2$ que havia sido determinada (Long et al, 2005b). Neste modelo, diferentemente do que havia sido proposto para o $\mathrm{K}_{\mathrm{v}} \mathrm{AP}$, o segmento S4 está disposto paralelamente à membrana e os seus aminoácidos positivos estão completamente, ou pelo menos parcialmente, isolados da membrana plasmática, para que suas cargas estejam protegidas do ambiente lipídico (Elinder et al, 2001; Laine et al, 2004). Para que este modelo seja validado, o segmento S4 deve estar de um lado interagindo com os segmentos S5 e S6 e do outro lado com os segmentos S1 e S3. Dessa forma, o segmento S4 fica confinado a uma fenda que permite que seus aminoácidos carregados se movam através da membrana sem expô-los ao ambiente lipídico (Long et al, 2005b). Essa interação do segmento $S 4$ com os segmentos $S 5$ e $S 6$ e o acoplamento entre os segmentos S4 e S5 são importantes para a comprovação de que os movimentos do domínio sensor de voltagem e do domínio do poro do canal ocorrem separadamente, porém estão acoplados (Long et al, 2005b).

Agora, se pensarmos como este sensor de voltagem reage ao campo elétrico transmembranar numa situação em que a membrana se encontra despolarizada, ou seja, com o interior celular carregado positivamente. Os aminoácidos do segmento S4 (que também são carregados positivamente) irão sofrer repulsão e se deslocarão para o meio extracelular, causando a abertura do poro ("gating") em consequência ao deslocamento dos segmentos S5 e S6, os quais estão acoplados ao S4. Por outro lado, quando ocorrer a repolarização da membrana, os resíduos de aminoácidos positivos do S4 se deslocarão e ficarão mais próximos do meio intracelular. Durante este 
deslocamento, denominado de desativação do canal, a região de acoplamento entre os segmentos S4 e S5 comprimem suas hélices internas e o poro do canal se fecha (Figura 4) (Laine et al, 2003; Long et al, 2005b).

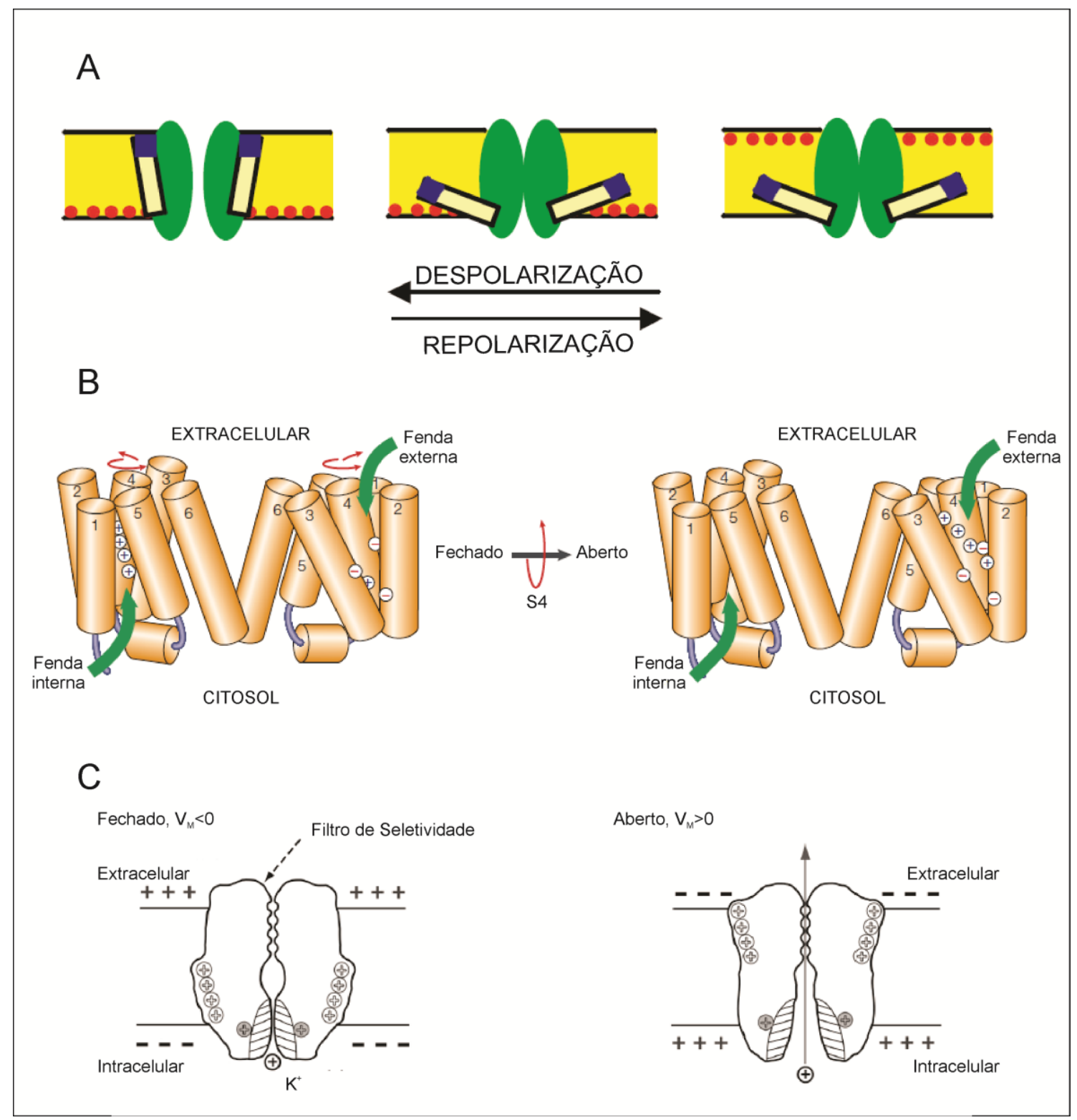

Figura 4 - Localização do sensor de voltagem. A - Modelo ilustrativo da localização e deslocamento do segmento S4 do canal $\mathrm{K}_{\mathrm{v}} \mathrm{AP}$. O segmento S4 se encontra na interface entre o citoplasma e a membrana plasmática e é capaz de se deslocar mais de $15 \AA$ ao longo da membrana plasmática, durante sua despolarização (Jiang et al, 2003b). B - Modelo ilustrativo proposto para a localização do segmento $S 4$ do $\mathrm{K}_{\mathrm{v}} 1.2$, o qual está disposto paralelamente à membrana plasmática (Long et al, 2005b). C - Modelo atualmente aceito para 
o deslocamento do segmento S4 durante a despolarização da membrana plasmática. Quando a voltagem da membrana for menor negativa $\left(\mathrm{V}_{\mathrm{M}}<0\right)$, o canal se encontra no estado fechado e as "gating charges" encontram-se próximas ao meio intracelular. Quando ocorre a despolarização da membrana, o segmento S4 desloca-se em direção ao meio extracelular. Figura modificada de (Chanda et al, 2005; Choe, 2002; Dryga et al, 2012).

\section{Ativação}

O processo de ativação do canal é dependente de voltagem e pode ser dividido em duas partes: (1) a alteração da conformação do sensor de voltagem e (2) o movimento dos segmentos S5 e S6 do canal ("gating"). Inicialmente, a despolarização da membrana causa uma alteração da conformação do sensor de voltagem, resultando no movimento de cargas ('gating charges') ao longo do campo elétrico da membrana plasmática. Conseguintemente a esta redistribuição de cargas ao longo do campo elétrico, tem-se o movimento dos segmentos S5 e S6, causando a abertura do poro. É possível, portanto, afirmar que estes dois mecanismos ocorrem separadamente, porém são energética e mecanicamente acoplados (Yellen, 1998).

A alteração da conformação estrutural do sensor de voltagem está relacionada à ativação do canal, uma vez que o segmento $\mathrm{S} 4$ do sensor de voltagem está acoplado aos segmentos S5 e S6. Este acoplamento se dá através de uma sequência padrão formada por três aminoácidos: Pro $-X-$ Pro, sendo que $X$ pode ser qualquer aminoácido. A comprovação deste acoplamento se deu através de mutações nestes aminoácidos, as quais causaram drásticas mudanças na cinética de ativação do canal (Liu et al, 1997; Schoppa \& Sigworth, 1998).

Outros experimentos também envolvendo mutagênese sítio - dirigida dos aminoácidos dos segmentos S5 e S6 permitiram inferir que a região do "gating" de ativação do canal, responsável pelo processo de abertura e fechamento do poro, é formada por aminoácidos específicos presentes na alça de ligação entre os segmentos S4 e S5 e, principalmente por alguns aminoácidos presentes no segmento S6, ao final de sua porção hidrofóbica, 
próxima ao meio intracelular. Ensaios eletrofisiológicos utilizando-se o TEA, o 4-Aminopiridina (4-AP) e o íon $\mathrm{Cd}^{2+}$ corroboraram os resultados previamente obtidos, uma vez que estes compostos se mostraram apenas capazes de bloquear a passagem dos íons $\mathrm{K}^{+}$após a ativação do canal (canal no estado aberto), ou seja, os seus sítios de ligação encontram-se inacessíveis quando o canal está no estado fechado (Figura 5) (Holmgren et al, 1996; Liu et al, 1997).

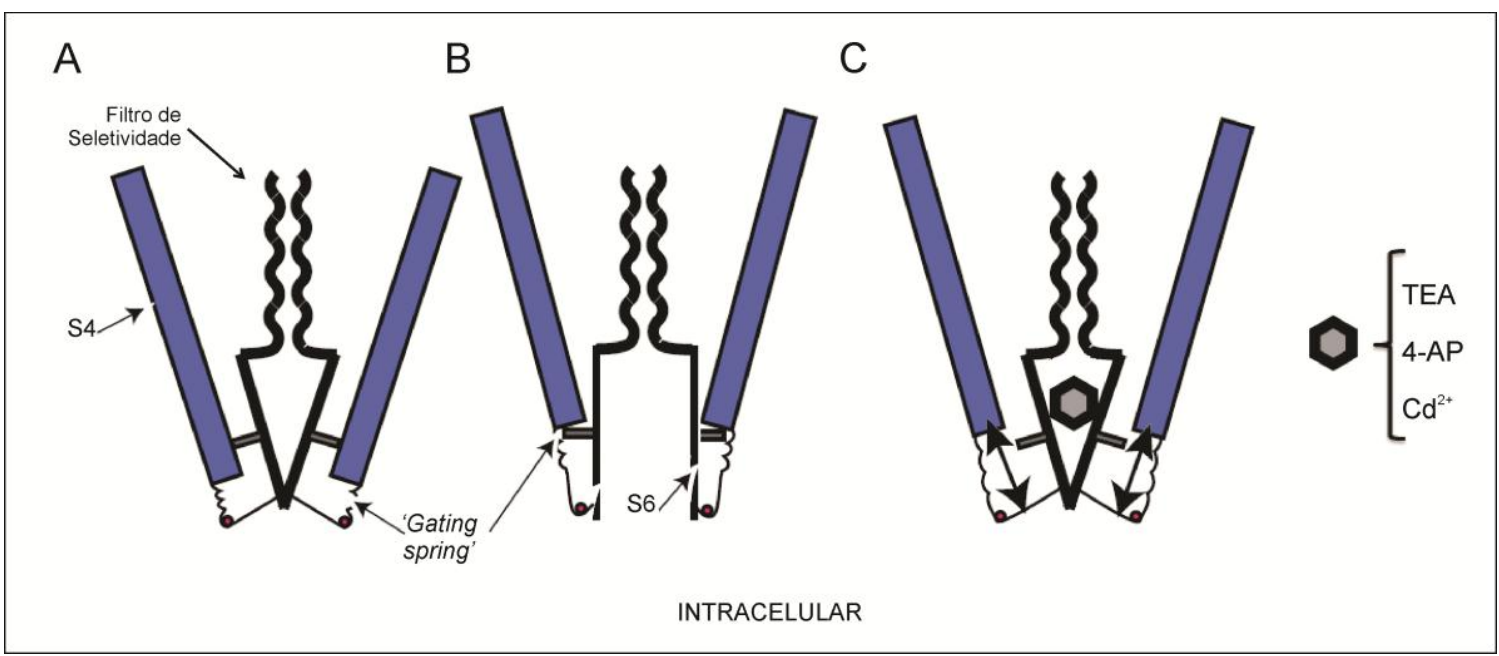

Figura 5 - Mecanismo de ativação do $\mathrm{K}_{\mathrm{v}}$. A - Representação esquemática do canal no estado fechado. Segmento S4 encontra-se próximo ao meio intracelular e os segmentos S6 estão próximos uns aos outros. B Representação do canal no estado aberto. O segmento $S 4$ desloca-se para o meio extracelular e o segmento S5 e S6 sofrem alterações de conformação estrutural que permitem a passagem dos íons $\mathrm{K}^{+}$. C - Comprovação do mecanismo de ativação do $\mathrm{K}_{\mathrm{v}}$. O sítio de ligação do TEA, 4-AP e o íon $\mathrm{Cd}^{2+}$ somente esta acessível quando o canal se encontra no estado aberto. Figura modificada de (Armstrong, 2003).

\section{Inativação}

O processo de inativação é a tendência dos canais se fecharem em resposta a uma prolongada despolarização da membrana. O mecanismo envolvido neste processo está acoplado à ativação do canal, uma vez que é através da ativação mediada pelo domínio sensor de voltagem, que se tem o controle indireto da inativação do canal (Yellen, 1998). 
O processo de inativação mediada pela porção Amino-terminal do canal é denominado de "N-type" ou "Ball-and-chain", pois é caracterizado por um bloqueio intracelular da região do poro do canal, por intermédio de uma porção da cadeia polipeptídica da região $\mathrm{N}$-terminal do canal (Choi et al, 1991). Esta porção é formada pelos 20 primeiros aminoácidos de cada uma das subunidades do canal, sendo que os onze primeiros são hidrofóbicos ou não carregados, seguidos por oito aminoácidos hidrofílicos ou carregados positivamente (Hoshi et al, 1990).

As primeiras evidências da existência desse mecanismo surgiram: (1) através de experimentos com a utilização de células tratadas com protease no meio intracelular, o que tornava os canais incapazes de inativarem, enquanto sua ativação era mantida inalterada (Armstrong \& Bezanilla, 1977; Armstrong et al, 1973; Hoshi et al, 1990) e, (2) utilizando-se derivados do TEA cujo bloqueio da corrente do canal era dependente de seu estado de conformação estrutural (Liu et al, 1997).

Posteriormente, a comprovação desse mecanismo se deu através (1) da deleção genética dos primeiros 20 aminoácidos da porção $\mathrm{N}$-terminal do canal, os quais ocasionaram a perda do mecanismo de inativação e, da adição intracelular de um peptídeo solúvel com a mesma sequência, capaz de restaurar a inativação dos canais com a deleção genética (Zagotta et al, 1990) e (2) da competição pelo sítio de ligação entre a região $\mathrm{N}$-terminal do canal responsável pela sua inativação e bloqueadores intracelulares ou pelo aumento na concentração de íons $\mathrm{K}^{+}$no meio extracelular (Choi et al, 1991; Demo \& Yellen, 1992).

O processo de inativação mediada pela região Carboxi-terminal do canal é denominado de "C-type". Este foi primeiramente caracterizado em mutantes de canais da subfamília Shaker sem o processo de inativação "N-type", mas que ainda assim eram capazes de inativar o canal, porém em uma escala temporal muito maior (segundos ao invés de milissegundos) (Hoshi et al, 1991). A inativação "C-type", assim como a "N-type", está energeticamente acoplada ao processo de ativação do canal (Yellen, 1998). Porém, o processo "C-type" 
ocorre no meio extracelular, como comprovado pela competição pelo sítio de ligação com o TEA, quando presente no meio extracelular (Lopez-Barneo et al, 1993).

Esse processo está relacionado a mudanças de conformações estruturais do Filtro de seletividade, uma vez que este se torna incapaz de conduzir a passagem dos íons $\mathrm{K}^{+}$, pois sofre uma constrição da região extracelular. Mutações dos aminoácidos do Filtro de seletividade ou próximos a ele causaram uma aceleração na cinética de inativação do canal e, uma diminuição na corrente total de íons $\mathrm{K}^{+}$que passa através do poro, comprovando-se a participação do Filtro de seletividade nesse mecanismo de inativação (Pardo et al, 1992; Perozo et al, 1993).

Yellen e colaboradores (2002), ao analisarem a conformação estrutural no estado aberto do canal de $\mathrm{K}^{+}$ativado por $\mathrm{Ca}^{2+}$ (MthK), isolado da bactéria Methanobacterium thermoautotrophicum, propuseram um terceiro tipo de inativação mediada pelo segmento S6. No entanto, este mecanismo de inativação é o processo inverso da ativação do canal, também mediada pelo segmento S6 e, por isso, a existência deste terceiro mecanismo de inativação é questionada pela comunidade científica (Figura 6) (Jiang et al, 2002b; Yellen, 2002). 